\title{
An evaluation of Population Services Zimbabwe's mobile outreach model
}

Ravikanthi Rapiti

Saiqa Mullick

Population Council

Follow this and additional works at: https://knowledgecommons.popcouncil.org/departments_sbsr-rh

Part of the Demography, Population, and Ecology Commons, Family, Life Course, and Society Commons, International Public Health Commons, Maternal and Child Health Commons, and the Women's Health Commons How does access to this work benefit you? Let us know!

\section{Recommended Citation}

Rapiti, Ravikanthi and Saiqa Mullick. 2014. "An evaluation of Population Services Zimbabwe's mobile outreach model." Nairobi: Population Council. 

(P) USAID

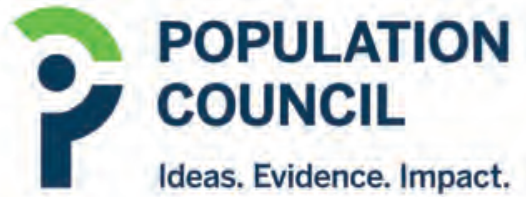
ThI MARIE STOPES INTERNATIONAL

\section{An evaluation of Population Services Zimbabwe's mobile outreach model}

Population Council September 2014

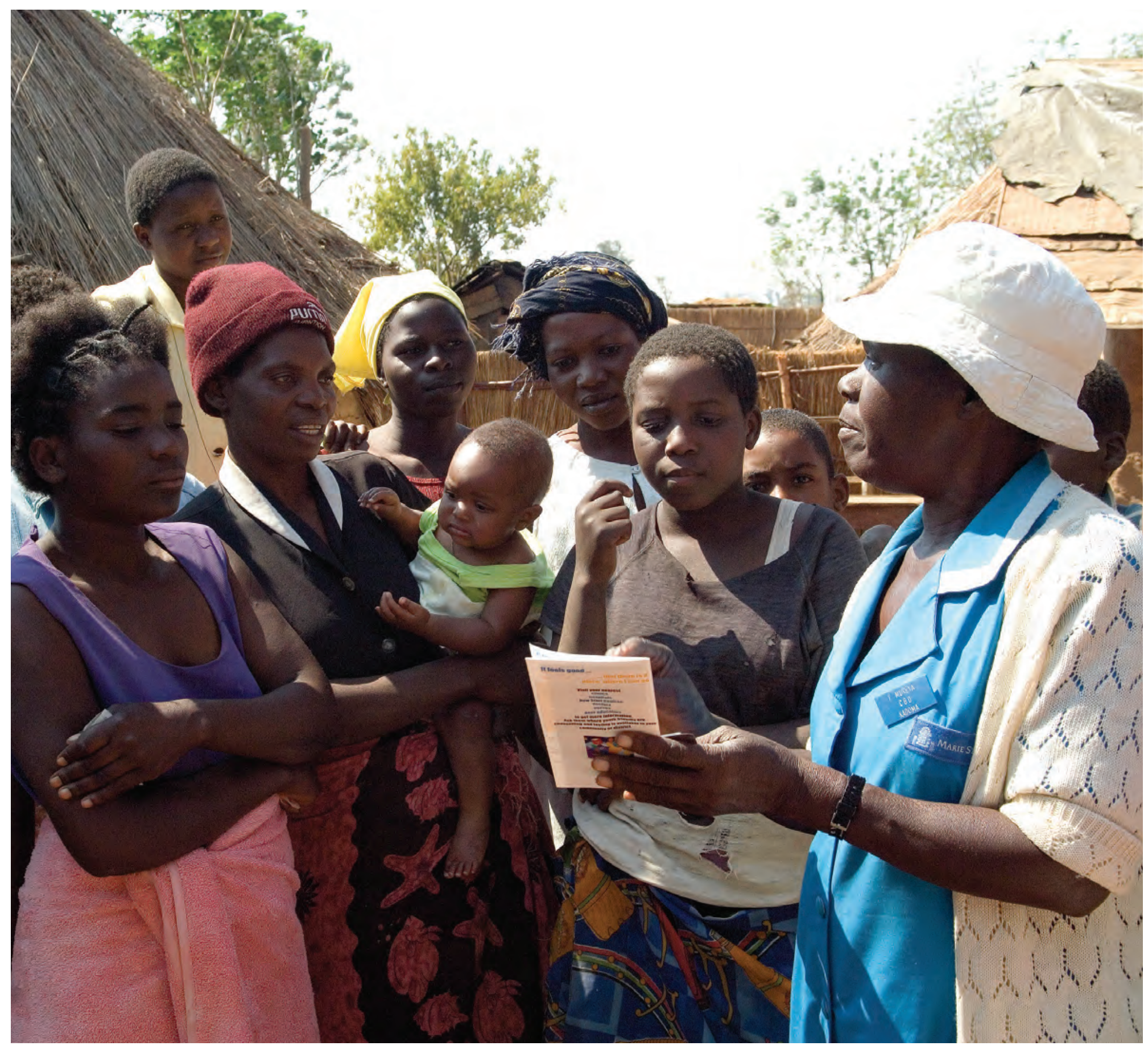




\section{Acronyms}

$\begin{array}{llll}\text { AE } & \text { Adverse Event } & \text { PC } & \text { Population Council } \\ \text { ANC } & \text { Antenatal Care } & \text { PID } & \text { Participant Identification Number } \\ \text { CPR } & \text { Contraceptive Prevalence Rate } & \text { PM } & \text { Permanent Method } \\ \text { DHS } & \text { District Health System } & \text { PSZ } & \text { Population Services Zimbabwe } \\ \text { HIV } & \text { Human Immunodeficiency Virus } & \text { QTA } & \text { Quality Technical Assistance } \\ \text { IUD } & \text { Intrauterine Devices } & \text { STI } & \text { Sexually Transmitted Infection } \\ \text { IRB } & \text { International Review Board } & \text { SRH } & \text { Sexual and Reproductive Health } \\ \text { LARC } & \text { Long Acting Reversible Contraception } & \text { TL } & \text { Tubal Ligation } \\ \text { MSI } & \text { Marie Stopes International } & \text { USAID } & \text { United States Agency for International } \\ \text { MoHCW } & \text { Ministry of Health and Child Welfare } & & \text { Development } \\ & & \text { ZDHS } & \text { Zimbabwe Demographic and Health } \\ & & & \text { Survey }\end{array}$

The Population Council confronts critical health and developmental issues, from stopping the spread of HIV to improving reproductive health and ensuring that young people lead full and productive lives. Through biomedical, social science, and public health research in 50 countries, we work with our partners to deliver solutions that lead to more effective policies, programs, and technologies that improve lives around the world. Established In 1952 and headquartered in New York, the Council is a nongovernmental, non-profit organization governed by an international board of trustees.

www.popcouncil.org

This study is made possible by the generous support from the American people through the United States Agency for International Development (USAID) under the terms of Cooperative Agreement AIDOAA-A-10-00059. The contents are the responsibility of the Population Council and do not necessarily reflect the views of USAID or the United States Government.

\section{Acknowledgements}

The Population Council would like to thank Dadirai Nguwo and the outreach teams from Population Services Zimbabwe, along with Marie Stopes International (MSI) Support for International Family Planning Organizations (SIFPO) staff including Anna Mackay, Gillian Eva and Julie Taft, for ongoing input into the research protocol and tools and in assisting to edit and finalise this document. Finally, thanks to Victoria James, Amos Milanzi and the New Dimension Consulting (NEDICO) team for the data management processes. In addition, Population Council extends its gratitude to the study participants who willingly gave their time to participate during the study.

\section{Suggested citation}

Rapiti, R., \& Mullick, S., (2014). An evaluation of Population Services Zimbabwe Mobile outreach model: Population Council.

\section{(c) 2014 The Population Council, Inc}

\section{Cover photograph credit}

Marie Stopes International

(c) Marie Stopes International 


\section{Contents}

1. Executive summary iv

2. Introduction 01

2.1 Population Services Zimbabwe 01

\begin{tabular}{l}
2.2 Study aims and objectives \\
\hline
\end{tabular}

3. Methodology 05

3.1 Study design, location and participants 05

4. Findings 0007

$\begin{array}{ll}4.1 \text { Study recruitment } & 07\end{array}$

4.2 Socio demographic characteristics 08

$\begin{array}{ll}4.3 \text { Previous contraceptive use } & 10\end{array}$

\begin{tabular}{l}
4.4 Quality of care \\
\hline Adverse events
\end{tabular}

4.5 Adverse events
4.6 Follow up care and health seeking behaviour by Day 15

4.6 Follow up care and health seeking behaviour by Day 15

$\begin{array}{ll}4.7 \text { Myths and misconceptions } & 18\end{array}$

5. Discussion and recommendations 20

$\begin{array}{ll}5.1 \text { Discussion } & 20\end{array}$

\begin{tabular}{l}
5.2 Conclusion \\
\hline .3 Recommendations
\end{tabular}

$\begin{array}{ll}5.3 \text { Recommendations } & 21\end{array}$

6. References 23

List of tables

Table 1: Family planning data for Harare, Masvingo, Matabeland South, Matabeland North and Zimbabwe 02

Table 2: PSZ clinical standards for mobile outreach 03

Table 3: Description of adverse events that clients were asked to report on 06

Table 4: Categories of adverse events 06

Table 5: Respondents recruited by outreach mobile sites, district province and outreach teams 07

Table 6: Client socio-demographic characteristics 09

Table 7: Provider observation on quality of care 13

Table 8: SRH services that were offered to clients seeking family planning services

Table 9: Types of adverse events experienced on the day of procedure 16

Table 10: Types of adverse events experienced at 15 days post procedure 16

Table 11: Implant clients self-report on menstrual bleeding and breast tenderness 17

Table 12: Myths and misconceptions as reported by the client 19

List of figures

Figure 1: Study cohort profile 08

Figure 2: Elements of the client focused approach 10

Figure 3: Quality of care for family planning services 11

Figure 4: Client history 12

Figure 5: Recommending PSZ family planning services 14

Figure 6: Reasons for clients not seeking health care when experiencing adverse event 18 


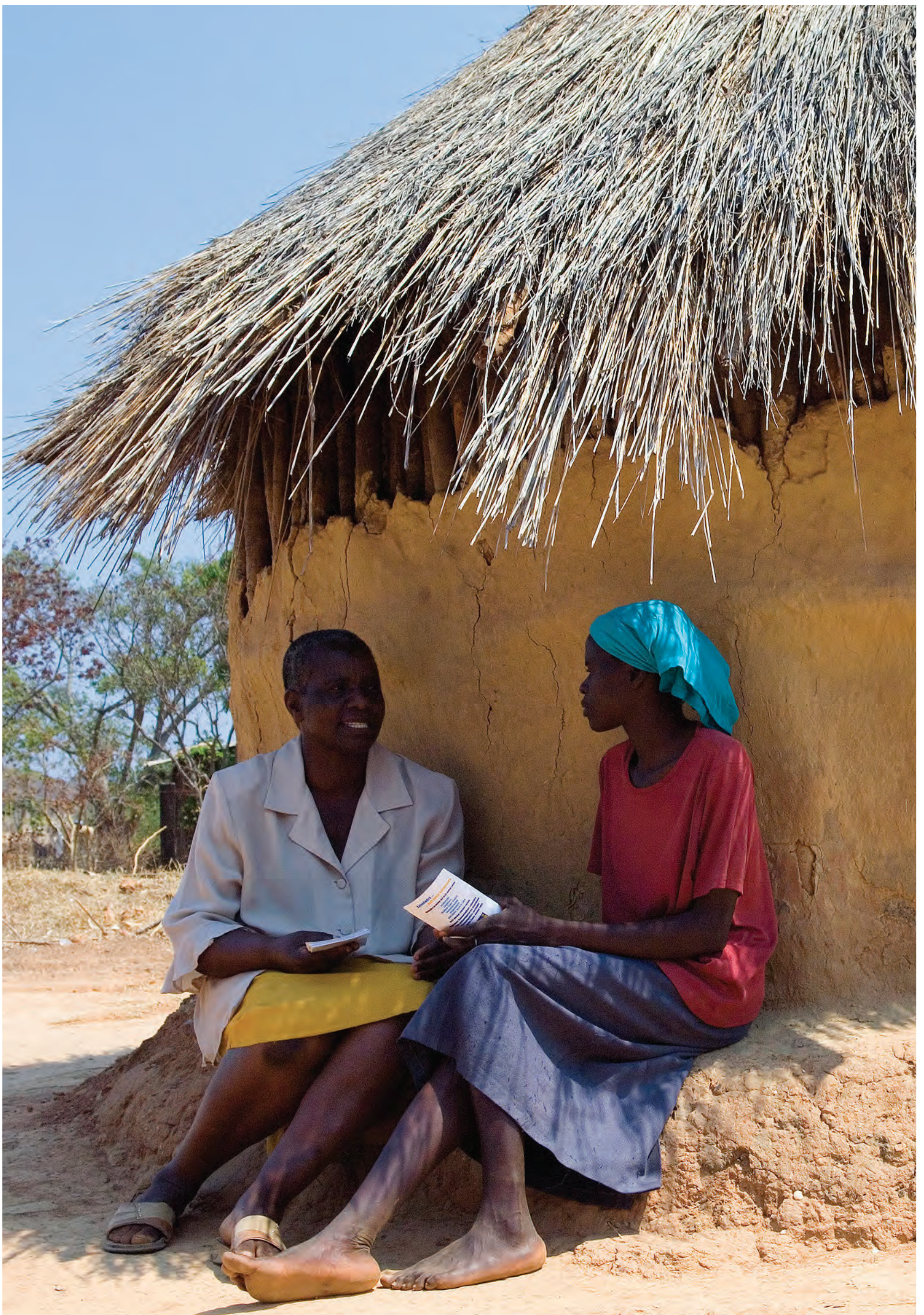




\section{Executive summary}

This report documents a service evaluation of Population Services Zimbabwe (PSZ) mobile outreach programme in four provinces of Zimbabwe. The evaluation was conducted by the Population Council between September and October 2013. This study was made possible through the United States Agency for International Development (USAID) funded Support for International Family Planning Organizations - Marie Stopes International (SIFPO-MSI) project. It provides key findings on the quality of the PSZ outreach programme in expanding choice and access to long-acting reversible contraceptives (LARCs) and permanent methods (PMs) of contraception, as well as recommendations for PSZ and other family planning programmes to consider in scaling up and strengthening mobile outreach services. The evaluation, conducted by Population Council, was designed to focus on various components of quality including adequate information and counselling on methods and services, good clinical procedure with minimal occurrence of adverse events, client healthseeking behaviour and client satisfaction. The level of integration of HIV and other SRH-related services into the family planning programme was also evaluated.

The fertility rate in Zimbabwe is 4.1 children per woman and the contraceptive prevalence rate (CPR) is 59\% [1]. The most recent Zimbabwe Demographic and Health Survey (ZDHS) 2010-2011 reported that if all married women with an unmet need for family planning were to use contraception, the CPR would increase from $59 \%$ to $74 \%$ [1]. Government-sponsored facilities in Zimbabwe remain the main providers of contraceptive methods, where $73 \%$ of all women who use modern contraceptive methods obtain them from the public sector. Integration of other services into sexual and reproductive health services, including HIV, has been outlined in the National Strategic Plan and other health policies through support of the Ministry of Health and Child Care (MOHCC). As a result, family planning services and clinics are now to provide HIV testing and counselling and other reproductive health services according to the 2011-2015 ZNASP [2].

Marie Stopes International (MSI) uses a mobile outreach model to increase the availability and choice of family planning services, with a particular focus on expanding access to LARCs/PMs among men and women living in rural and hard to reach areas. PSZ, a member of MSI Global Partnership, is one of
Zimbabwe's largest specialised SRH organisations, known for providing a wide range of high quality, affordable and client-oriented services. PSZ currently provides mobile outreach services through eight teams covering over 500 sites throughout the country. The mobile teams (consisting of four to five staff) complement the government's facility level services with a focus on areas where family planning is not otherwise available. The service includes providing short-term family planning services (pills, condoms, emergency contraception, and injectables), LARCs (implants, IUDs) and PMs (tubal ligation and vasectomy).

While expanding the availability of family planning methods is important, it is equally important that the quality of these services are maintained to ensure that family planning procedures are safe and meet the expectations of clients. Under the auspices of the USAID-funded SIFPO-MSI project, Population Council carried out an evaluation of PSZ's mobile outreach services in four provinces in order to inform and improve PSZ's family planning service provision. Between September and October 2013, 665 women receiving a tubal ligation, implant or IUD were recruited from high volume sites for the study. Data collection included observing client-provider interaction and service provision as well as interviewing clients immediately following the service on the day of the procedure. Clients were then asked to return 15 days post procedure, at which point they were interviewed about adverse events and health seeking behaviour.

The median age of clients was 26 years and $43 \%$ had a child less than a year old. All except one client (664) reported having living children of which $22 \%(n=145)$ reported having one living child and 31\% $(n=207)$ had two living children. 23\% $(n=153)$ reported having three living children and $11 \%(n=74)$ reported having four living children. $40 \%$ of clients reported that they planned to have a child "more than five years from now". Most women in the study had achieved primary or secondary education, with clients from rural areas achieving a lower educational status (primary) compared to those from urban areas. 39\% $(n=260)$ of clients reported having discussed seeking family planning services with their partner/spouse.

Information on HIV testing and sexual risk behaviour was collected during the client exit interview. 95\% of 
clients reported that they had been tested for HIV at some point in the past. $19 \%$ of clients reported having more than one partner in the past 12 months. Condom use was low as only half of the women $(49 \%, n=272)$ reported "ever" having used a condom (male or female) of which only $29 \%(n=79)$ reported "always" using a condom and $24 \%$ reported that they had unprotected sex in the last three months. This indicates that clients may be at significant risk of HIV and would likely benefit from HIV-related information and services.

Data from the client exit interviews showed that $91 \%$ of clients chose an implant as their preferred method of contraception, $7 \%$ chose an IUD and 1\% chose tubal ligation. Client satisfaction was high, with $100 \%$ reporting that they would use the PSZ family planning services again. However, only $68 \%$ reported that they would refer the family planning service to a friend; $57 \%$ reported that they would refer a family member; and $21 \%$ reported they would tell a stranger about the service.

To assess quality of care including information provided and level of integration of HIVISRH services, research nurses observed client-provider interactions.

Specifically, to measure integration of services, it was observed whether clients received HIV and AIDS counselling, counselling on dual protection, pregnancy testing, gender-based violence and STI services (information, testing \& treatment). The presence of obstetrics and breast cancer history screening was also assessed. For all the clients (100\%), it was observed that they were provided with information on the risks and benefits of the chosen method of contraception as well as the risks and benefits of using male or female condoms as a single or dual method of protection against HIV. $61 \%$ of clients were provided with HIV and AIDS counselling. 58\% of clients were observed being asked about STIs. 94\% of clients were asked about their obstetric history and $62 \%$ of clients were provided information on gynecological issues including obstetrics and breast cancer. In only $12 \%$ of observations gender based violence (GBV) issues were discussed. In client exit interviews, $95 \%$ of clients reported that they were told by the providers on how to manage side effects they may experience after receiving their choice of family planning method.
As indicated from client exit interviews, a significant proportion of clients had misconceptions regarding the various contraceptive methods that persisted after the group education and counselling. Some commonly reported beliefs included: women who have never had a baby cannot use an IUD or DMPA and IUDs cause discomfort to the partner during sex. Some clients felt that hormonal contraceptives could cause cancer and as many as $29 \%$ of clients said pills can make a woman sterile.

During the Day 15 follow-up visits, 91\% of clients $(\mathrm{N}=555)$ returned, all of whom were asked if they had experienced a side effect ${ }^{1}$ and if so, whether they had sought care when they had experienced the side effect. 386 clients reported experiencing symptoms at some point (i.e. on day of procedure up to and including Day 15 follow up). Most clients reported experiencing expected side effects on the day of the procedure. $32 \%(n=180)$ of clients indicated that they experienced a side effect up to Day $15.96 \%$ of clients did not experience a side effect requiring follow up treatment.

Of the $4 \%(n=24)$ who did experience a side effect requiring follow up one half called the PSZ helpline to enquire about the side effect/s they had experienced. Of those who called the helpline, half returned to the facility and were seen by a facility provider prior to the Day 15 follow up visit. One percent of all women $(n=8)$ experienced a constant temperature and fever and had to visit the health facility to have the method removed. These eight clients reported no longer experiencing these side effects on the 15 day follow up visit. Five of these eight clients reported being satisfied with the follow up treatment they received from the facility provider. One client, an IUD acceptor, reported that the PSZ provider had observed a moderate hematoma or bruising. This required wound revision and the release of a build-up of blood and the treatment and care was provided by the nurse from the PSZ team at the Day 15 follow up.

The study demonstrated that the quality of service and client satisfaction is high amongst all those that received family planning services from PSZ mobile outreach sites. Clients were able to articulate the management of side effects during the client exit interview on Day 1 . The data reveals that there is

\footnotetext{
Side effects are defined as symptoms that are a result of the procedure or drug that is generally not a sign of a health problem, nor related to the skill of the provider, and requires resting or no medical intervention or treatment. The client may be aware of the problem all the time but still able to do normal daily activities
} 
some level of HIV and SRH integration into the PSZ model of family planning, however not all clients are being offered all services. Most clients that experienced side effects were aware of how and where to seek health services prior to their Day 15 follow up visit. Although a high number of adverse events were reported, the majority were categorised as either "very mild" or "mild" and constituted expected side effects of the family planning method or procedure. There were no serious complications reported.

\section{Recommendations for PSZ:}

- Stronger integration of SRH services such as HIV and STI counselling and testing could provide an opportunity to intensify HIV prevention activities amongst family planning clients such as HIV re-testing and condom use.

- Only 39\% ( $\mathrm{n}=260)$ reported having discussed family planning with their spouse or partner. Therefore a recommendation may be to include spouses or partners in family planning campaigns to involve them in the family planning services women receive with the aim to strengthen HIV and $\mathrm{SRH}$ integration.

- A significant proportion of clients continue to have misconceptions and incorrect information about the various contraceptive methods. PSZ health care providers should continue to focus on correcting myths and misconceptions routinely in group or individual counselling as part of their family planning community outreach activities.

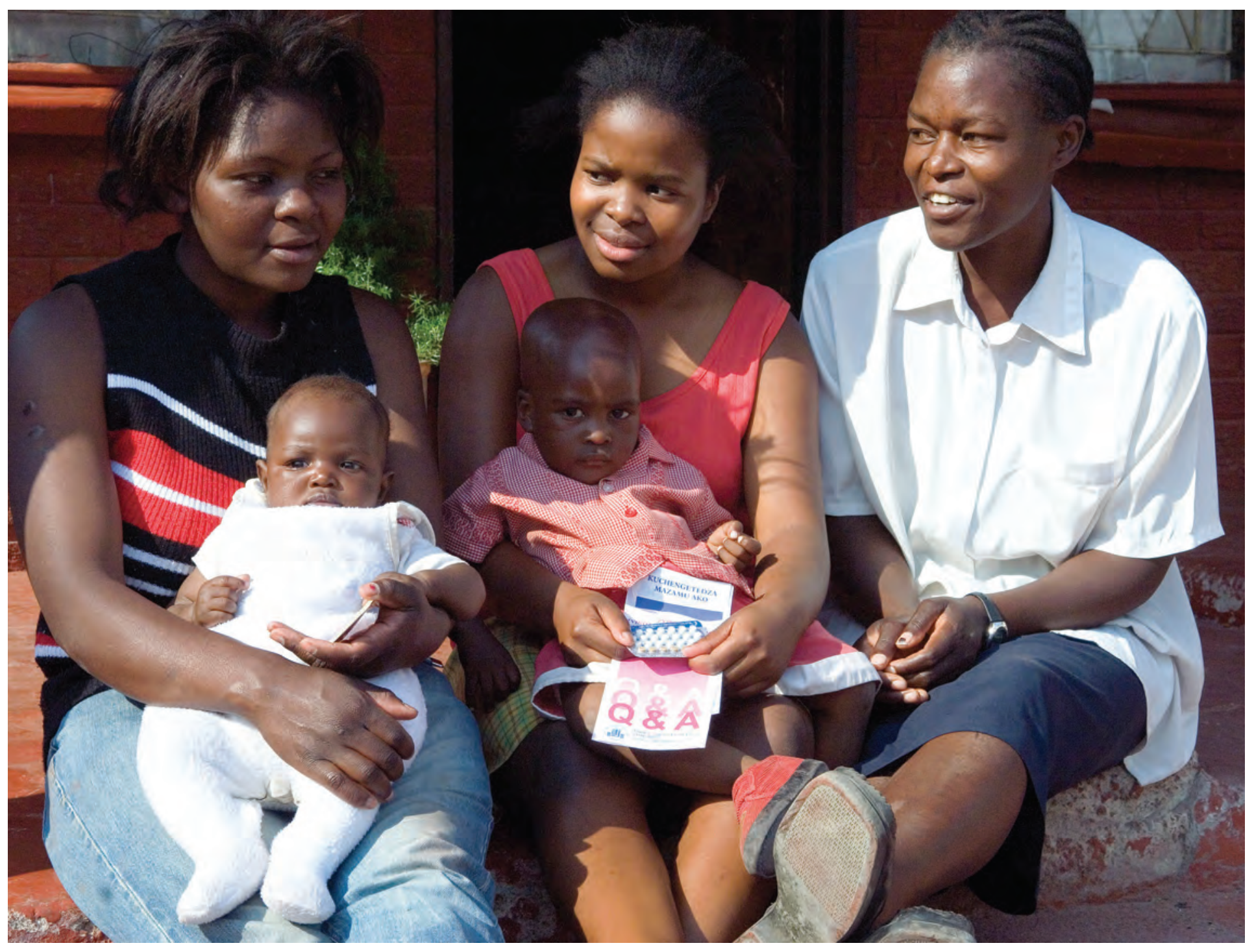




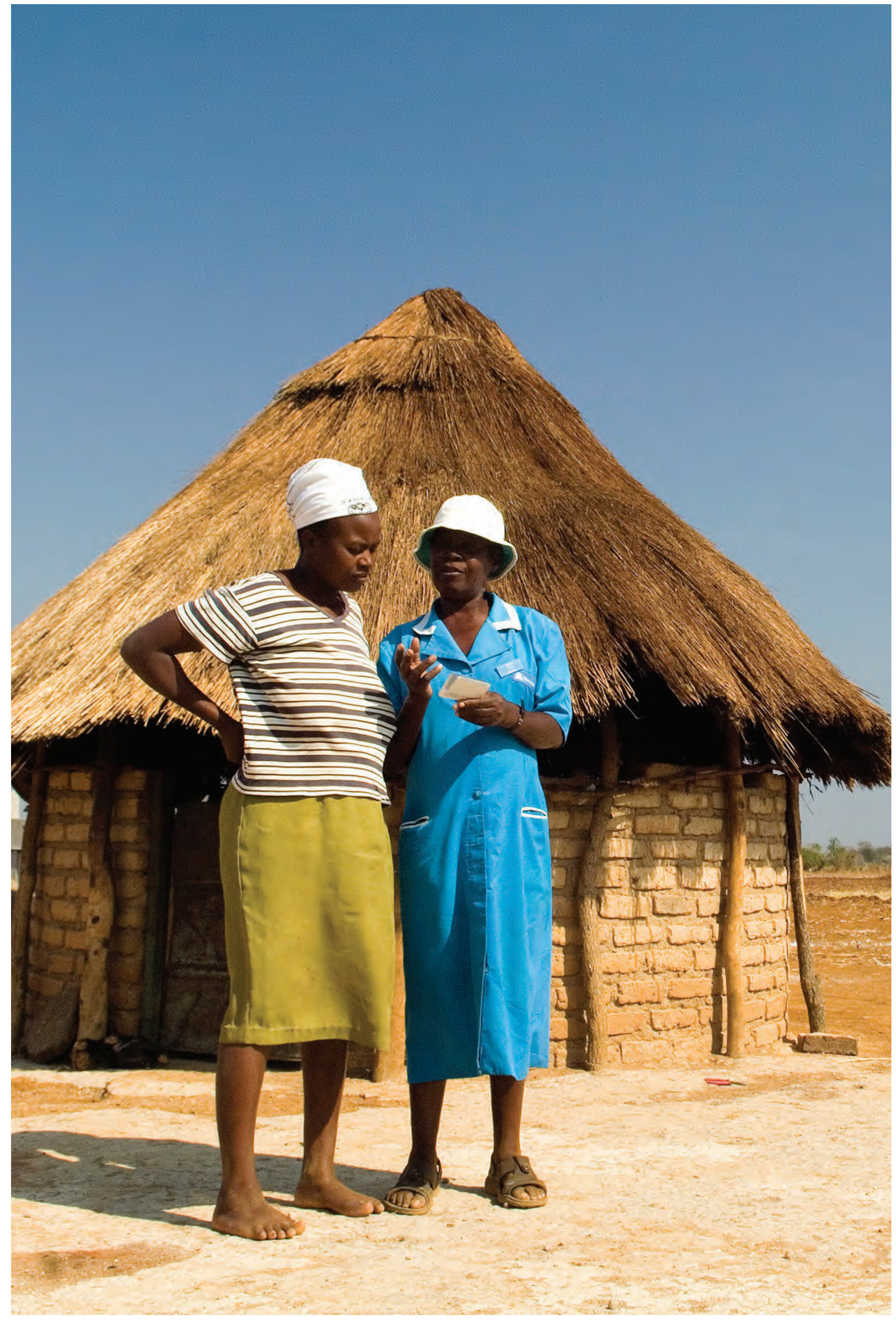




\section{Introduction}

Zimbabwe has a population of 13 million [1]. 41\% of the population is below the age of 15 years, $55 \%$ are between 15 and 64 years and $4 \%$ are 65 years or older [1]. The adolescent population is estimated to be $1,656,000$ and the number of women of reproductive age (15-49 years) is approximately 3,246,000 [3]. The total fertility rate is 4.1 children per woman. For women in Zimbabwe, childbearing during ages 20-24 years and 25-29 years is at its peak and then drops sharply after the age of 39 years. Fertility among urban women is markedly lower (3.1 children per woman) as compared to rural women (4.8 children per woman). Zimbabwe's CPR is $59 \%$ and the proportion of women with an unmet family planning need is $13 \%$ [1]. The Demographic Health Surveys define unmet need for family planning as "all fecund women who are married or living in union, and thus presumed to be sexually active, who either do not want any more children or who wish to postpone the birth of their next child for at least two more years but are not using any method of contraception" [1], [3]. Approximately 211,000 women want to delay or avoid falling pregnant but do not have access to modern methods of contraception [4]. Fertility has fallen among women over the age of 20 years in the past two decades, although there has been a noticeable increase among those between 15 and 19 years [6]. Trends reveal that fertility declined between 1988 and 2005/6, from 5.4 children to 3.8 children per woman, but increased in 2010/11 to 4.1 children per woman [1]. The Zimbabwe Demographic and Health Survey (ZDHS) 2010-2011 reported that contraception use in Zimbabwe has remained unchanged since 2005/6, and that if all married women with an unmet need for family planning were to use a contraceptive method, the CPR would increase from $59 \%$ to $74 \%$.

Education levels are closely linked to a woman's fertility: women with no formal education and women with a primary education have between five and six children, respectively, while women with at least some secondary education have approximately four children or less [1]. In addition, women and/or their partners in poor socioeconomic circumstances are less likely to use contraception [7], specifically if the women are over 35 years old, less educated, own less household items, and live in rural areas [8]. In Zimbabwe, 98\% of women and $99 \%$ of men know about at least one contraception method [1]. Most of the women in rural areas depend on mobile clinics and community based distribution for their contraceptive supplies, while those in urban areas get their supplies from clinics and pharmacies [9]. Government-sponsored facilities remain the main providers of contraception with $73 \%$ of women who use modern contraceptive methods obtaining them from the public sector [1]. Table 1 overleaf provides with an overview of family planning in Zimbabwe and four of its provinces i.e. Harare, Masvingo, Matebeland South and Matebeland North.

Zimbabwe has monitored the HIV epidemic to assess HIV prevalence in pregnant women attending antenatal care (ANC) services. The country has a generalised heterosexually driven HIV epidemic with a prevalence of $14 \%$ [1]. 95\% of women attended ANC at least once during their most recent pregnancy [5] and an estimated 1,159,097 adults and children were living with HIV and AIDS in 2011 [10]. While family planning programmes have led to an increase in the percentage of women using contraceptives and improvements have been in the use of LARCs/PMs that are preferred by clients, these offer no protection against HIV [11].

In Zimbabwe, women from all backgrounds are subject to violence, where $27 \%$ of women reported that they have experienced sexual violence at some point in their lives and only $37 \%$ of women who have ever experienced any physical or sexual violence have sought help from any source [1]. Addressing gender dynamics and the related issue of gender based violence as part of integrated $\mathrm{SRH}$ services within family planning [12], has been included in Ministry of Health and Child Welfare (MoHCW) policies [13], as experiencing violence increases a woman's' risk to HIV and reduces contraceptive use [14].

\subsection{Population Services Zimbabwe}

PSZ, a member of Marie Stopes International, is one of Zimbabwe's largest specialised SRH organsations, PSZ currently provides mobile outreach services in nine of Zimbabwe's ten provinces through eight teams visiting over 500 sites at different times. The districts are covered through a network of eight static clinics and eight mobile outreach teams and take place in $\mathrm{MoHCW}$ clinics, schools, private facilities, outdoors with temporary structures etc. Expansion of these sites is currently underway. PSZ aims to increase access to family planning services for women, men and adolescents in rural and hard-to-reach communities. Mobile outreach services make use of an integrated 
TABLE 1: Family Planning data for Harare, Masvingo, Matabeland South, Matabeland North and Zimbabwe
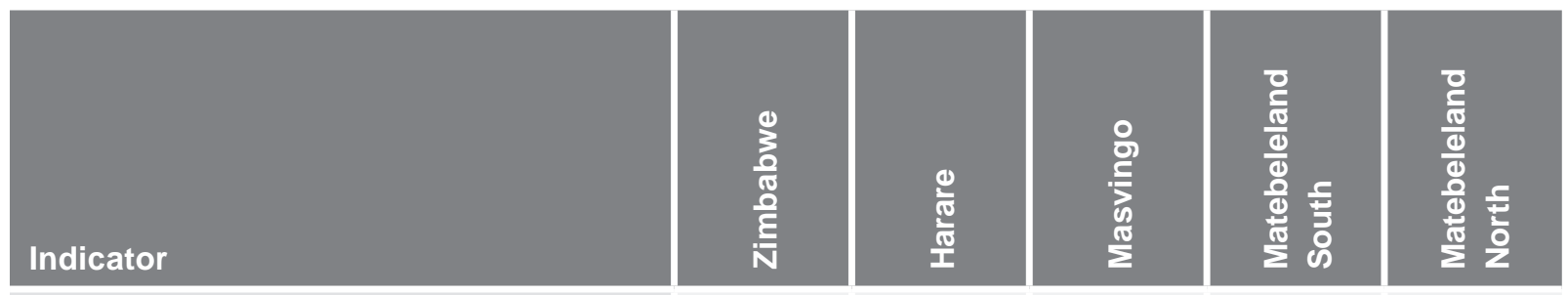

\begin{tabular}{l} 
Total fertility rate per woman \\
\hline Contraceptive prevalence rate (\%) \\
\hline (CPR) for modern methods \\
\hline Female sterilisation \\
\hline
\end{tabular}

\begin{tabular}{l|l}
4.1 & 3.1
\end{tabular}

$59 \quad 59$

$59 \quad 54$

4.2

4.1

57

58.2

54

46

51

0.9

IUD

0.9

1.1

54.0

45.2

49.3

0.2

Male sterilisation

0

Pill

27.3

Injection

Male Condom

6.1

Male Condom

Female Condom

Traditional methods (withdrawal, periodic abstinence)

\begin{tabular}{|l|} 
Total unmet need for family planning \\
Unmet need for spacing births \\
\hline Unmet need for limiting births
\end{tabular}

Maternal mortality ratio (MMR)

0.3

1.2

1.2

0.7

0

0.2

0.8

27.3

45.8

4.4

19.8

6.13 .5

3.5

7.6

19.8

27.6

3.5

3.2

7.6

15.7

12.2

0.3

0.4

1.7

4.3

1.6

0.8

1.

0.2

0

0

1.2

0.2

1.0

1.4

\begin{tabular}{|l|l|l|l|l|}
\hline 12.8 & 12.6 & 11.7 & 26.2 & 13.2 \\
\hline 5.5 & 7.1 & 9.0 & 13.7 & 6.2 \\
\hline
\end{tabular}

7.3

5.5

2.7

12.5

7.0

960 per 100,000 live births 
approach that combines community based information education and communication (IEC) and service provision. PSZ provides the full method mix of family planning services (eg. condoms, pills, injectables, implants, IUDs and PMs) through its outreach mobile sites. PSZ has also embraced the global call for repositioning family planning through integration of STI and HIV services. Currently PSZ employs the syndromic approach per national guidelines to screen and treat for STIs. Mobile service delivery involves having contraceptives provided by a team of trained providers, either through periodic visits to a lower-level facility or from a mobile unit itself in an area with limited or no family planning services. Typically, a PSZ outreach mobile clinic consists of a team of four and a vehicle equipped to provide contraceptive services, including LARCs/PMs, which often complement the readily available short term methods and broaden available methods and choices for women. Depending on the location and methods provided, teams are usually staffed by nurse aide, clinical officers, or physicians, and a driver.

PSZ implements a quarterly internal quality technical assistance (QTA) and an annual external QTA that assesses infrastructure, supplies, procedure correctness and inputs for an effective programme. However, this does not include independent verification of aspects of quality of counselling and information. Additionally, the understanding of information on relevant services, HIV integration, referrals, and information on client and provider behaviour in the event of a side effect experienced by the client, has not been systematically documented. As part of their mobile outreach quality assurance programme, MSI undertook to evaluate the mobile outreach services in Zimbabwe, which are delivered at primary health care (PHC) facilities. Although this evaluation focused on services provided by PSZ outreach teams, it aims to contribute to the national knowledge base, especially in communities where PSZ conducts and will conduct future mobile outreach services. The evaluation will inform the national family planning programme, as well as the overall quality of services provided by PSZ nationally. In 2012, PSZ, added 268,919 couple years of protection for clients accessing family planning services [15]. The results from this evaluation are expected to guide PSZ on how to further strengthen their mobile outreach services and develop new strategies to enhance service delivery standards. Table 2 documents the processes PSZ undertakes for mobile outreach services.

TABLE 2: PSZ clinical standards for mobile outreach

Pre-procedure steps:

1. Comprehensive group family planning counselling: information is provided on all family planning methods, including benefits and drawbacks, myths and misconceptions by a PSZ staff member.

2. Client registration.

3. One-to-one counselling: Clients are individually counselled using a client-centred approach, more detailed information is provided regarding the method chosen by the client (including side effects) by a PSZ health care provider.

4. History taking and medical check-up/screening.

5. Voluntary and Informed consent obtained (given in writing by the client for permanent methods per MoHCW standards).

6. Medical tests as required, including urine and blood tests.

7. Anaesthesia provision (when indicated by method).

Post procedure follow-up care:

All clients at PSZ outreach sites complete registration and the recording of PSZ services are documented in the registers. All clients are counselled post procedure on how to deal with side effects and instructions for after care. They are also given the contact telephone number of the PSZ Helpline and PSZ Team Leader in case they were in need of contacting a PSZ provider.

Tubal ligation clients Provided with pain relief, anti-inflammatory medication, tablets.

IUD clients

All IUD clients are counselled to return to the facility at six weeks post procedure and are attended by MoHCW nurses. Three month and one-year follow ups occur when PSZ returns to the outreach site.

Provided with pain relief medication 


\subsection{Study aims and objectives}

This study was commissioned to complement PSZ's regular quality assurance procedures for outreach services in Zimbabwe. The external evaluation, conducted by Population Council, was designed to focus on various components of quality including adequate information and counselling on methods and services, good clinical procedure with minimal occurrence of adverse events and client satisfaction with the services provided by outreach clinics.

Additionally, health seeking behaviour of clients was evaluated in the event that side effects were experienced. The findings of the study are intended to be used by PSZ to improve quality of outreach services. Quality was measured through data collection of direct observation of client counselling and service provision, client exit interviews on the day of service and at a 15 day follow-up visit.

Objective 1: To evaluate the quality of services (service provision and counselling) provided to clients attending mobile outreach services for a range of family planning methods provided by the PSZ mobile health teams.

\section{- Sub-objectives}

- Assess the quality and levels of satisfaction with regard to counselling and information provided.

- Assess information provided to clients on what steps to take if they experienced a side effect.

- Assess the level of integration of HIV services into contraceptive or other SRH services.

Objective 2: Measure the occurrence of side effects associated with LARCs/PMs up to 15 days postprocedure with an emphasis on understanding health seeking behaviour for side effects.

\section{- Sub-objectives}

- Measure the timing, frequency and type of side effects occurring between 0 to 15 days.

- Assess women's health-seeking behaviours when experiencing a side effect.

- Determine access to follow-up care for women with a side effect. 


\section{Methodology}

\subsection{Study design, location and participants}

This evaluation involved recruiting a convenience sample of 665 women receiving family planning services from PSZ mobile outreach sites between September and October 2013. Of all the provinces PSZ is working in, the four provinces with highest coverage, Harare, Masvingo, Matebeleland North and Matebeleland South were selected on account of having sites in which a high number of clients accessed family planning services during the period January to July 2013. Additionally, these provinces provided a representation of urban, peri-urban and rural areas.

Women were eligible to participate in the study if they had received a family planning service, signed an informed consent and indicated that they were willing to return for the 15 day follow up visit.

\section{Sampling}

The sample size was guided by logistic considerations and the need to ensure that the study evaluated the quality of care provided by all eight PSZ mobile teams. A sample size of 665 clients was achieved during the data collection period, which represents an average of 83 women per mobile team.

\section{Survey instrument, data collection and data analysis}

Each PSZ outreach team had an accompanying research team of five people in total consisting of three female data collectors, one nurse and one team leader who carried out recruitment, conducted client exit interviews and 15 day follow-up interviews. Clients were recruited for the study prior to their procedure at the outreach site, and following informed consent, were observed whilst receiving counselling and family planning service provision. During the client-provider observation, the nurse explained her presence to the clients and provided assurance that the privacy and confidentiality of all study participants would be maintained throughout the process.
During the procedure, the research nurse completed the client-provider observation tool which included questions on how the provider greeted and assessed the client, family planning method selection and client counselling and observation of specific processes. Following the procedure, clients were interviewed about their background characteristics; knowledge and source of information about the outreach services; previous use of contraception, satisfaction of the service they had just received, experience of immediate adverse event and reasons for opting to receive the service from $\mathrm{PSZ}$. Clients receiving tubal ligation were given adequate time for recovery (a minimum of 45 minutes) post-procedure prior to conducting the exit interview. All clients were asked to return to the clinic 15 days post-procedure and received a follow-up card. The cost of travel for this interview was covered by the study. At the Day 15 follow up interview, the interviewer collected information on side effects, health care seeking behaviour, resumption of normal activities and satisfaction. If clients did not return to the site for a follow up interview, attempts were made to contact respondents by telephone only if the client had agreed to be contacted during informed consent. At the Day 15 follow up visit, all clients that returned were asked to consent again.

Data collection was conducted between 9th and 17th September 2013. All data related to adverse events (side effects or complications) on the day of the procedure, at post-procedure or those that "still existed" at the Day 15 follow up visit were collected through client interviews. Table 3 provides a description of adverse events that the clients were asked to self-report on which was related to their choice of family planning method. 
TABLE 3: Summary description of adverse events that clients were asked to report

\begin{tabular}{|c|c|c|c|}
\hline $\begin{array}{l}\text { Type of family } \\
\text { planning }\end{array}$ & Implant & IUD & Tubal Ligation \\
\hline 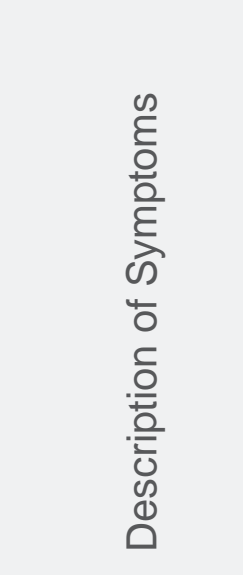 & $\begin{array}{l}\text { Pain at insertion site } \\
\text { Bleeding at insertion site } \\
\text { Menstrual cycle (change in } \\
\text { bleeding) } \\
\text { Scarring } \\
\text { Change in breast since } \\
\text { implants (eg. tenderness or } \\
\text { lumps) } \\
\text { Change in blood pressure } \\
\text { Infection (eg. Fever, pain, } \\
\text { redness or discharge at } \\
\text { insertion site) } \\
\text { Expulsion of implants }\end{array}$ & $\begin{array}{l}\text { Pain at time of insertion } \\
\text { Pain (related to cramping post- } \\
\text { insertion) } \\
\text { Vaginal bleeding } \\
\text { Infection (eg. Fever, abdominal } \\
\text { pain, discharge) } \\
\text { Expulsion of IUD }\end{array}$ & $\begin{array}{l}\text { Pain at time of } \\
\text { insertion } \\
\text { Pain (related to } \\
\text { cramping post- } \\
\text { insertion) } \\
\text { Vaginal bleeding } \\
\text { Infection (eg. Fever, } \\
\text { abdominal pain, } \\
\text { discharge) } \\
\text { Expulsion of IUD }\end{array}$ \\
\hline
\end{tabular}

Data collection was conducted between 9th and 17th September 2013. All data related to adverse events (side effects or complications) on the day of the procedure, at post-procedure or those that "still existed" at the 15 day follow up visit were collected through client interviews. Table 3 provides a description of adverse events that the clients were asked to self-report on which was related to their choice of family planning method.

TABLE 4: Categories of adverse events ${ }^{2}$

\begin{tabular}{|l|l|}
\hline Type of adverse event & $\begin{array}{l}\text { Description } \\
\text { Very mild }\end{array}$ \\
\hline $\begin{array}{l}\text { The client experiences low level of discomfort that does not require any medical } \\
\text { intervention }\end{array}$ \\
\hline Mild & $\begin{array}{l}\text { The client experiences some level of discomfort that only requires resting or minimum } \\
\text { level of medical intervention such as taking pain relief from a medical shop }\end{array}$ \\
\hline Moderate & $\begin{array}{l}\text { The client experiences more frequent level of discomfort that requires attention from } \\
\text { medical personnel, such as a doctor }\end{array}$ \\
\hline Severe & $\begin{array}{l}\text { The client experiences frequent level of discomfort that requires either further medical } \\
\text { check-up or hospitalisation }\end{array}$ \\
\hline
\end{tabular}

The study design, development of survey tools and data collection was managed by the Population Council. Data was entered on data collection templates developed in Epi Info 7. Descriptive statistical methods were conducted using the Statistical Package (STATA Version 12). 


\section{Findings}

\subsection{Study recruitment}

The sample was recruited from four provinces: Harare, Masvingo, Matabeland South and Matabeland North. The evaluation was conducted at 26 mobile outreach sites in eight districts. The majority of services were delivered in rural locations (77\%) with the remaining delivered in urban and peri-urban areas (24\% and $7 \%$ respectively). The facility level distribution of implant, IUD and tubal ligation clients recruited for the study is provided in Table 5 .

TABLE 5: Respondents recruited by outreach mobile sites, district province and outreach teams. Distribution of tubal ligation, IUD and implant clients recruited for the study by district

\begin{tabular}{|c|c|c|c|}
\hline $\begin{array}{l}\text { Mobile Outreach } \\
\text { Teams by Province }\end{array}$ & District & Mobile Team Sites & $\begin{array}{l}\text { Number of } \\
\text { Respondents }\end{array}$ \\
\hline \multirow{6}{*}{$\begin{array}{l}\text { 1. Masvingo Outreach } \\
\text { Teams }\end{array}$} & \multirow[t]{6}{*}{ Chiredzi } & Chinzvinzvi & 18 \\
\hline & & Chiredzi Poly & 44 \\
\hline & & Ndali & 29 \\
\hline & & Rupangwana & 24 \\
\hline & & St Joseph & 30 \\
\hline & & Feversham & 27 \\
\hline \multirow{8}{*}{$\begin{array}{l}\text { 2. Harare Outreach } \\
\text { teams }\end{array}$} & \multirow[t]{5}{*}{ UMP } & Mashambanhaka & 24 \\
\hline & & Nyanzou & 8 \\
\hline & & Chipfunde & 11 \\
\hline & & Manyika & 16 \\
\hline & & Nhakiwa & 28 \\
\hline & Seke & Beatrice & 20 \\
\hline & Mutoko & Mushimbo & 24 \\
\hline & Ruwa & Ruwa & 95 \\
\hline \multirow{6}{*}{$\begin{array}{l}\text { 3. Nkulumane Outreach } \\
\text { teams }\end{array}$} & \multirow[t]{5}{*}{ Umguza } & Insiza & 37 \\
\hline & & St James & 10 \\
\hline & & Hope Fountain & 25 \\
\hline & & Durban and Queens Mine & 12 \\
\hline & & Kensington & 29 \\
\hline & Lupane & St Lukes & 46 \\
\hline \multirow{5}{*}{$\begin{array}{l}\text { 4.Bulawayo Outreach } \\
\text { Teams }\end{array}$} & \multirow[t]{5}{*}{ Umzingwane } & Mzingwani & 12 \\
\hline & & Sibomvu & 40 \\
\hline & & Mawabeni & 23 \\
\hline & & Mbizingwe & 10 \\
\hline & & Habane & 23 \\
\hline TOTAL & & & 665 \\
\hline
\end{tabular}


During the study period 702 clients were recruited to participate in the study and out of these women, 665 were eligible to participate in the study. Those who were not eligible could not be provided with contraception due to medical reasons identified during the consultation or had decided not to receive a family planning method. Table 6 shows the distribution of the sample for the clients recruited in each of the outreach facilities. In total, $1 \%(n=7)$ of clients received a tubal ligation, $7 \%(n=48)$ of clients accepted IUDs and 92\% $(n=610)$ of clients opted for implants. At the 15 day follow up visit, $91 \%(n=555)$ of the required sample size returned to the facility. While all of the tubal ligation and IUD clients returned, 91\% of implant clients returned. 55 clients were loss to follow up (see Figure 1).

\subsection{Socio demographic characteristics}

The median age of clients was 26 years. Eight clients were aged between 14 and 16 years old which are included in the 15-19 year old group in the table below. Almost three quarters (74\%) of women were married and almost all had more than one child (99\%) (see Table 7). The number of living children clients had was fairly evenly distributed. The majority of clients had two children (31\%), while the remaining were evenly split between those having one child, three children or four or more children.

FIGURE 1: Study cohort profile

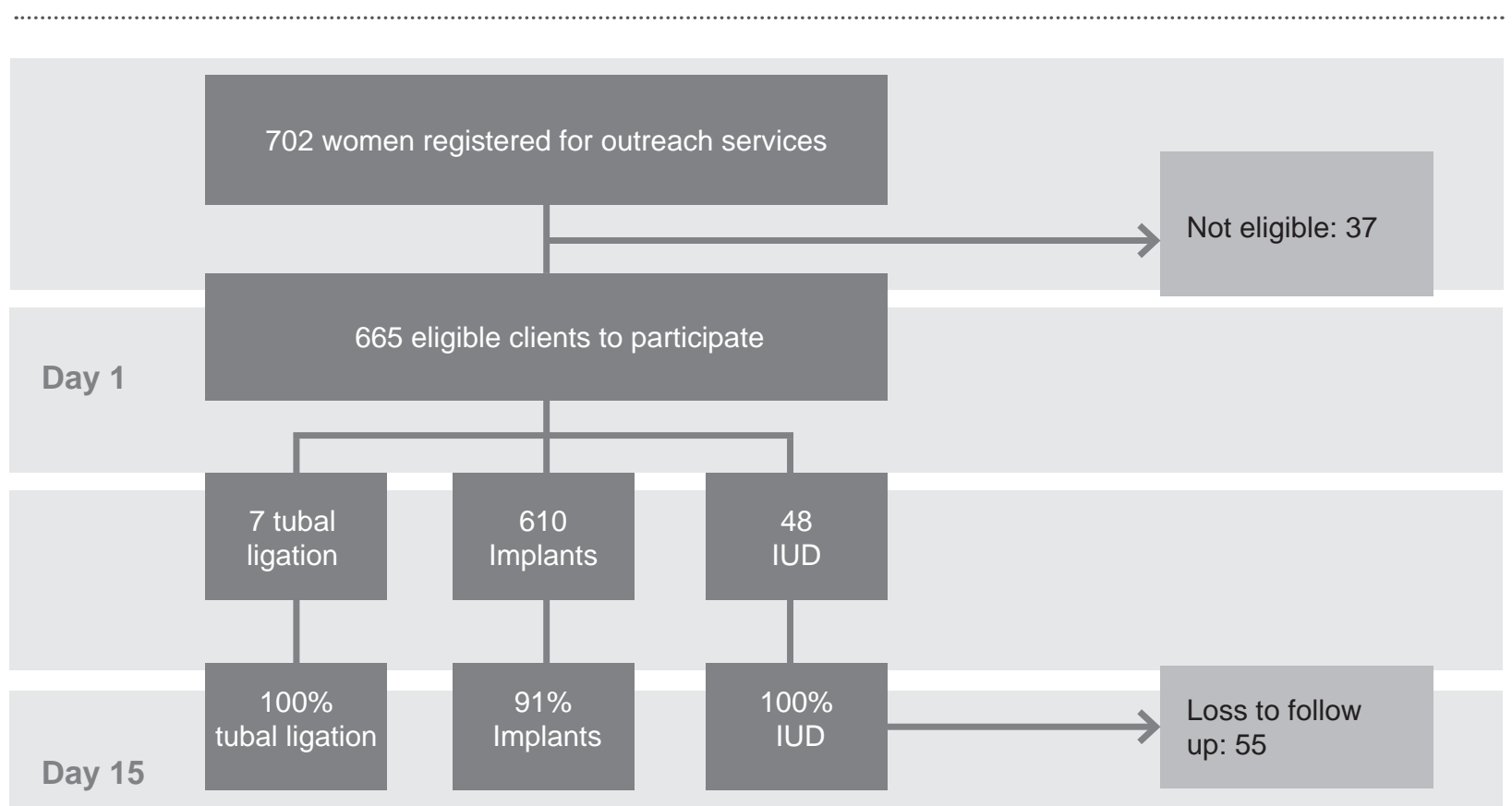




\section{TABLE 6: Client socio-demographic characteristics}

\begin{tabular}{|c|c|}
\hline Socio-demographic characteristics & \multirow{2}{*}{$\begin{array}{l}(\mathrm{N}=665) \%(n) \\
26 \text { years }\end{array}$} \\
\hline Age of women (years) [mean] & \\
\hline Under 20 (15-19) & $12 \%(n=77)$ \\
\hline $20-24$ & $31 \%(n=206)$ \\
\hline $25-29$ & $24 \%(n=157)$ \\
\hline 30- 34 & $17 \%(n=110)$ \\
\hline $35+$ & $17 \%(n=114)$ \\
\hline Number of living children [mean] & 3 \\
\hline 0 & $0 \%(0)$ \\
\hline 1 & $22 \%(n=145)$ \\
\hline 2 & $31 \%(n=207)$ \\
\hline 3 & $23 \%(n=153)$ \\
\hline 4 or more & $23 \%(n=145)$ \\
\hline \multicolumn{2}{|l|}{ Education } \\
\hline Primary & $39 \%(n=252)$ \\
\hline Secondary & $59 \%(n=384)$ \\
\hline Graduate & $1 \%(n=4)$ \\
\hline Technical education & $1 \%(n=9)$ \\
\hline Professional education & $1 \%(n=4)$ \\
\hline Other & $0 \%(n=1)$ \\
\hline \multicolumn{2}{|l|}{ Occupation } \\
\hline Housewife & $49 \%(n=324)$ \\
\hline Petty business & $8 \%(n=55)$ \\
\hline Business including retail shop & $1 \%(n=5)$ \\
\hline Farmer & $14 \%(n=94)$ \\
\hline Agricultural labourer & $7 \%(n=48)$ \\
\hline Teacher & $1 \%(n=4)$ \\
\hline Factory / Production worker & $0 \%(n=2)$ \\
\hline Managerial / Professional & $4 \%(n=23)$ \\
\hline Office attendant & $0 \%(n=2)$ \\
\hline Student & $1 \%(n=5)$ \\
\hline Other & $16 \%(n=103)$ \\
\hline Average monthly household income & USD 177. 88 \\
\hline$\%$ of clients living under $\$ 1.25 /$ day & $6 \%(n=33)$ \\
\hline$\%$ of clients living under $\$ 2.50 /$ day & $7 \%(n=36)$ \\
\hline \multicolumn{2}{|l|}{ Client risk Profile } \\
\hline Disclosing family planning to partner & $39 \%(n=260)$ \\
\hline Partner supportive of receiving family planning service & $39 \%(n=260)$ \\
\hline Clients reported ever receiving an HIV test & $95 \%(n=632)$ \\
\hline HIV test in last 12 months & $12 \%(n=78)$ \\
\hline last HIV test > 18 months ago & $58 \%(n=383)$ \\
\hline \multicolumn{2}{|l|}{ Self-reported sexual behaviour } \\
\hline One partner & $81 \%(n=481)$ \\
\hline Two partners in last 12 months & $9 \%(n=49)$ \\
\hline More than two partners in last 12 months & $1 \%(n=5)$ \\
\hline Unprotected sex in last 3 months & $24 \%(n=406)$ \\
\hline "ever" used condom & $49 \%(n=272)$ \\
\hline "always" used condom & $29 \%(n=79)$ \\
\hline
\end{tabular}




\subsection{Previous contraceptive use}

To measure the degree to which outreach services expand access and choice, particularly for LARCs/ PMs, clients were asked about prior contraceptive use. All of the women in the study reported having used a contraceptive method at some point prior to receiving the PSZ service. The majority of clients reported use of short-acting methods including the pill $(n=328)$, injectable $(n=94)$ and male condoms $(n=65)$. A minority of clients reported that they were using a long-acting method including IUD $(n=5)$ and implant $(n=54)$. Clients were also asked whether they had become pregnant whilst using a method of contraception in the past. $62 \%$ of women reported that they were using some form of contraception when they became pregnant. The contraceptive pill was cited most frequently as the failed method. Most of these women (85\%) reported switching to a LARC/PM after the unplanned pregnancy.

\subsection{Quality of care}

\section{Quality of counselling and information}

To evaluate quality of care, the provider-client interaction was observed to assess data collection on whether a client-focused approach was used, the quality of counselling and information, screening and eligibility and post-procedure counselling. The client provider observation tool was used by the research nurses during observation. Observation was conducted with all clients irrespective of the family planning method chosen and the interaction between the service provider and client during the procedure. Confidentiality and privacy during the procedure was also noted.

The client-focused approach specifically assessed whether the provider: used the client's name during the consultation; used a kind and inviting voice; listened to the client; encouraged the client to ask questions and assisted the client in making a decision when choosing an family planning method. Assisting clients in decision-making involves providers giving nonjudgmental and non-directive support to ensure clients make an informed choice and feel comfortable with their SRH decisions. Client-provider observation data indicates a generally high level of client-focused approach in which $95 \%$ of interactions included using a kind and inviting voice and listening to the client, and $83 \%$ encouraging clients to ask questions (see Figure 2).

Client-provider observations were supported with findings from the client exit interviews which included

FIGURE 2: Elements of the client focused approach

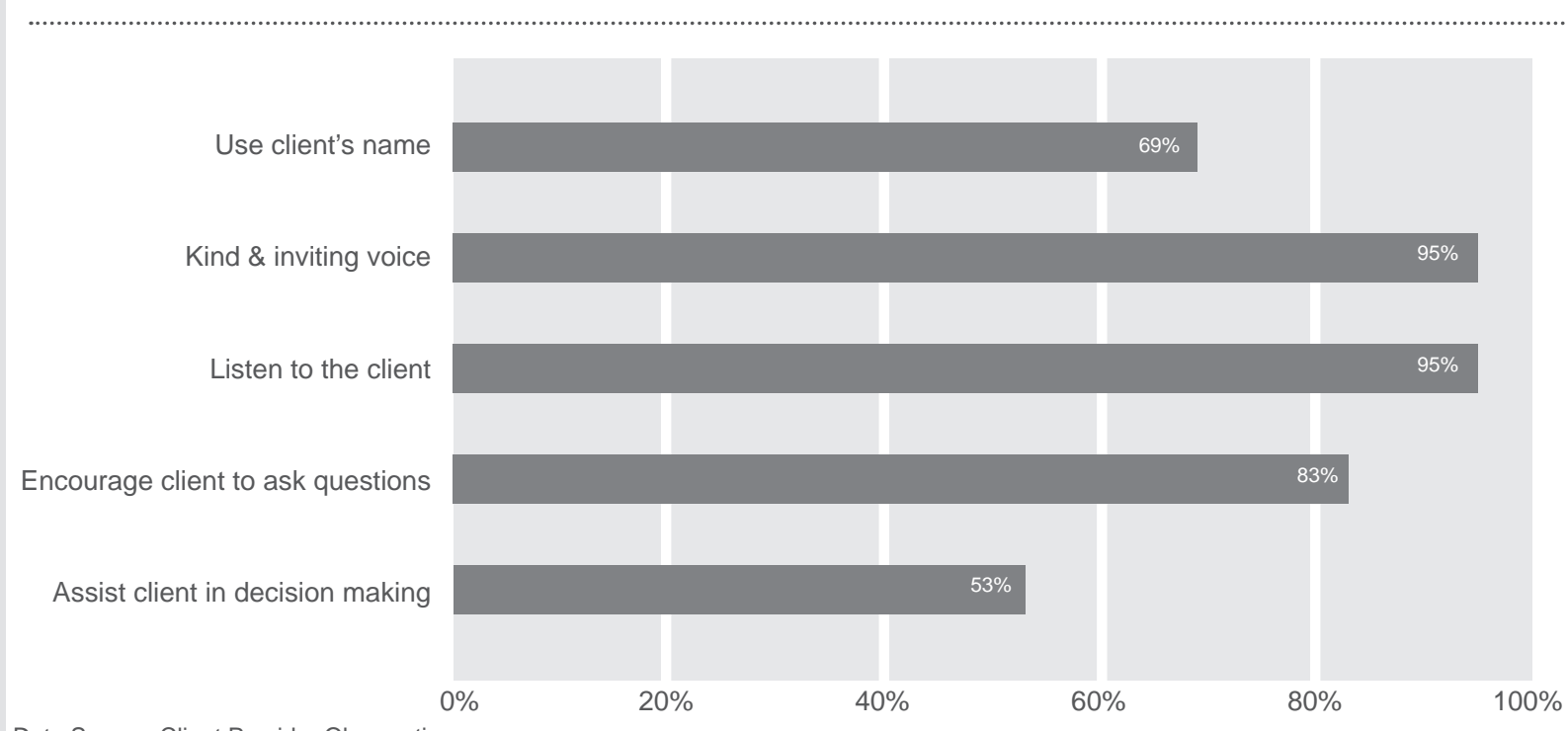


questions on client-centered approaches. Figure 3 shows the client reported data such as greetings and mannerisms the provider displayed.

Quality of counselling and information provided by providers was also found to be high. For all the clients (100\%), it was observed that they were provided with information on the risks and benefits of the chosen method of contraception as well as the risks and benefits of using male or female condoms as a single or dual method of protection against HIV. 94\% of interactions included provision of accurate information. From the client exit interviews, 93\% of clients reported that they were provided with adequate information on the different types of contraception available through the PSZ mobile outreach services, 92\% felt they were aware of the risks and benefits of the different contraception methods, side effects for each of the contraceptive methods provided by PSZ and what to do should they experience a side effect (95\%). This data was collected during the client exit interview after the client had received both group and individual counselling as well as the family planning method of their choice.

\section{Client history}

Most providers captured the required elements of the clients' medical history during the visit. It was observed that $94 \%$ of clients were asked about their obstetrics history followed by hypertension (83\%). Fewer than half of clients (43\%) were asked if they experienced migraines or headaches by the provider. Only $36 \%$ of

FIGURE 3: Quality of care for family planning services

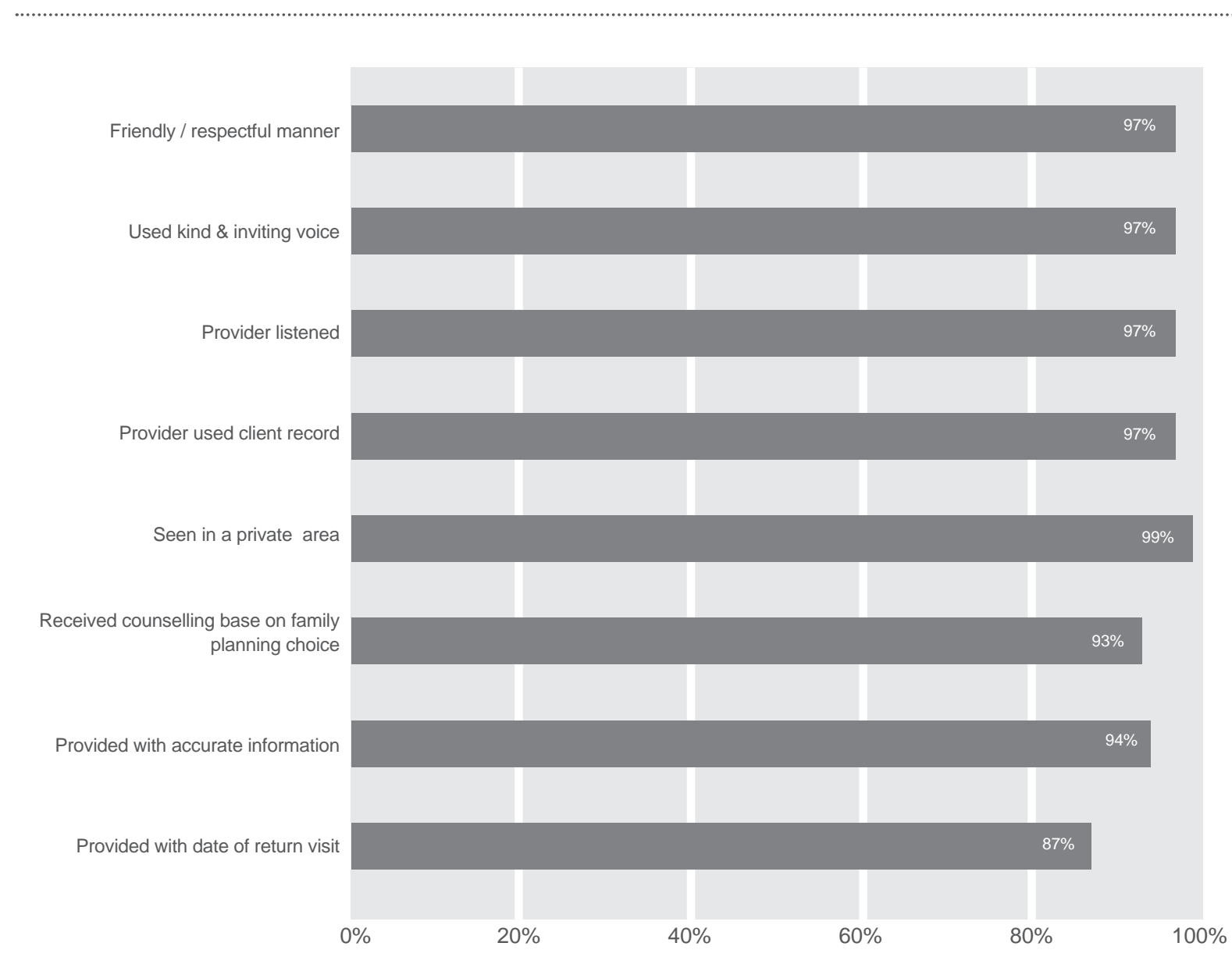


clients were asked whether or not they smoked. Figure 4 and Table 8 provide details on specific screening topics and history taking from client provider observations.

\section{Client satisfaction}

At enrolment all clients (100\%) stated that they were happy and satisfied with the family planning service, however only $21 \%$ of clients indicated that they would "recommend the service" to a stranger, $57 \%$ to a family member and $68 \%$ to a friend.

Client satisfaction was also recorded at the 15 day follow up visit among the clients that returned. When asked whether they would "recommend the family planning method" to other women all tubal ligation clients ( $n=7), 88 \%(n=38)$ of IUD clients and $89 \%(n=$ 471) of implant clients reported that they would recommend their family planning method to other women. However, one tubal ligation client, $6 \%(n=3)$ of IUD clients and $1 \%(n=8)$ of implant clients said they had some regret in having chosen their particular family planning method. These clients were asked no additional questions related to regret.

Overall satisfaction with the outreach service was the same for groups of women accessing tubal ligation, IUD and implant services, with 95\% of clients indicating that the quality of service they received was either as expected or better than expected.

Two percent $(n=6)$ of IUD clients were dissatisfied with the service due to the attitude of the provider. These clients $(n=6)$ also indicated additional reasons for

FIGURE 4: Client history

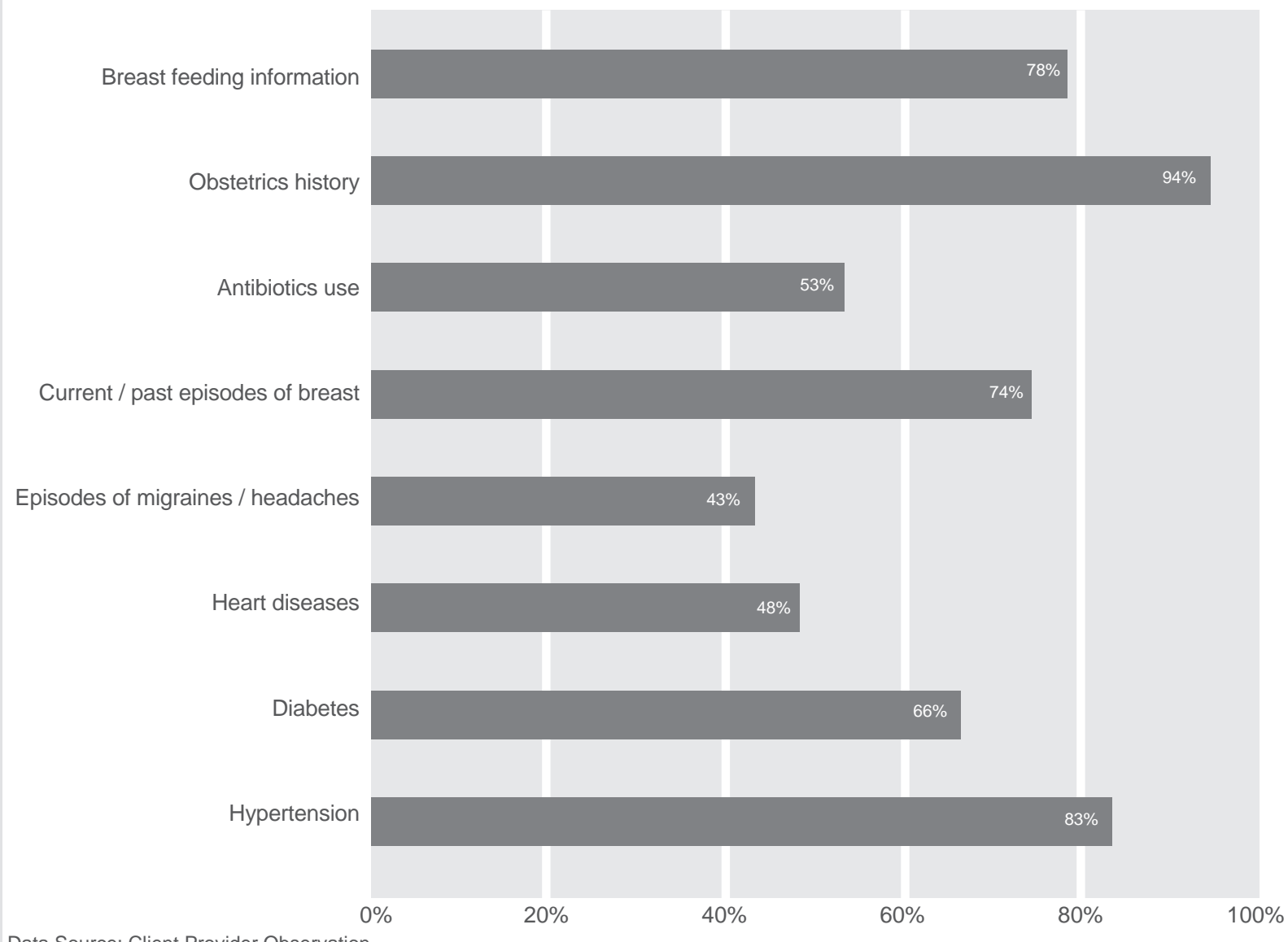


TABLE 7: Provider observation on quality of care

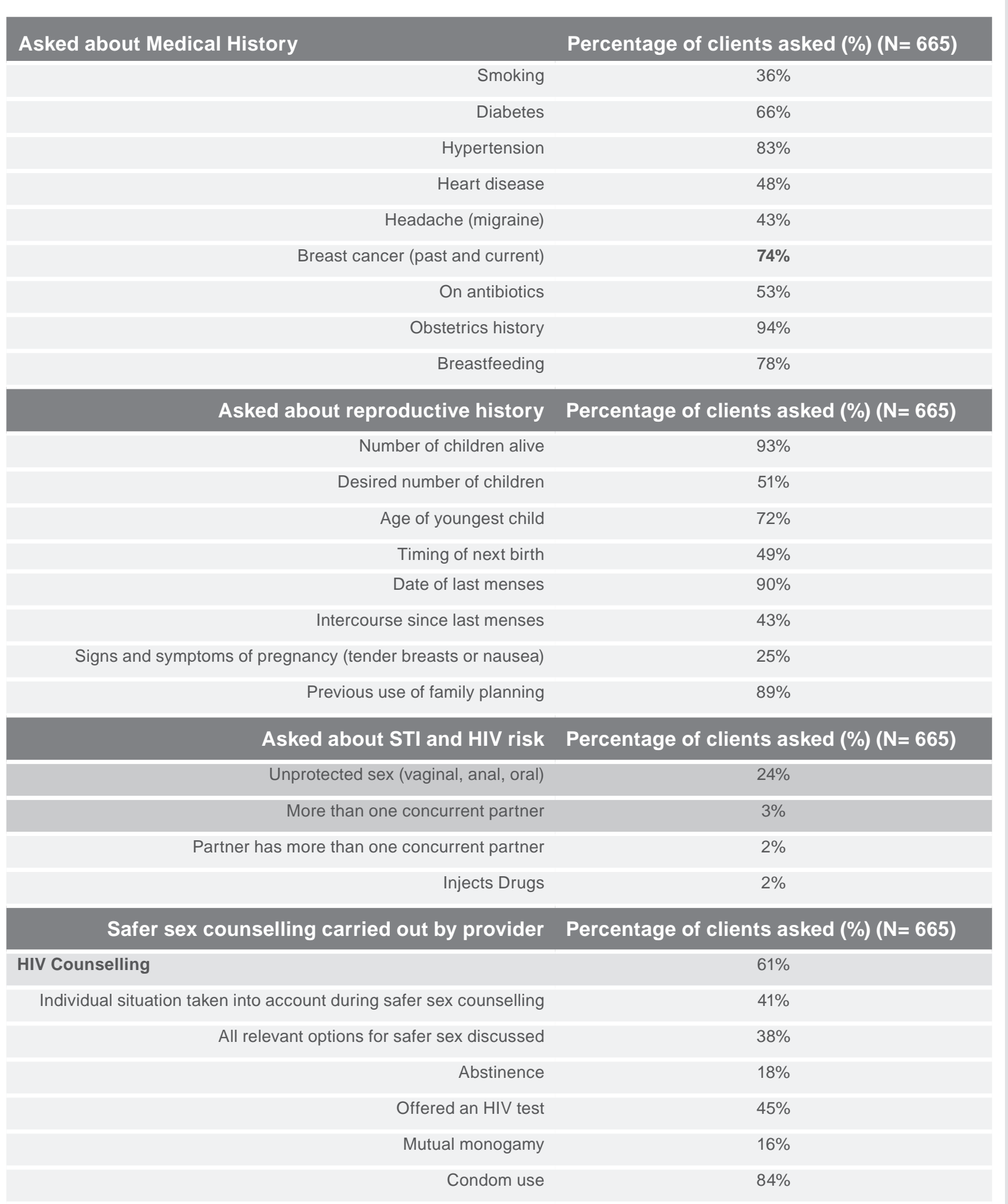




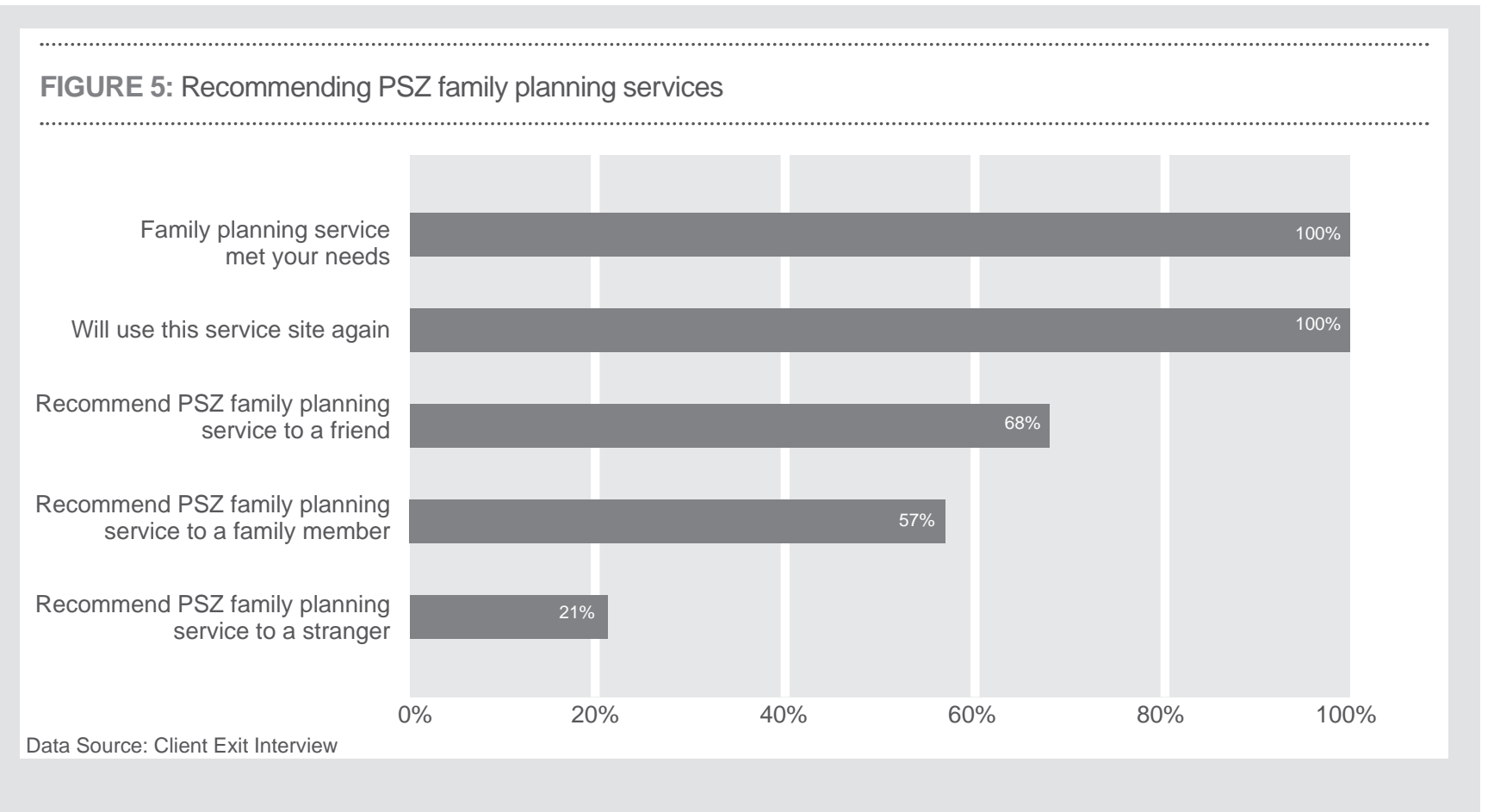

being unsatisfied with the service including the lack of transport to the site $(n=4)$, no provision of blankets during the procedure $(n=3)$ and insufficient financial compensation for travel to and from the site of service provision $(n=3) .^{3}$

\section{Level of integration of HIV services into contraceptive or SRH services}

Each client was observed on whether they received
HIV and AIDS counselling, counselling on dual protection, obstetrics history and breast cancer, pregnancy testing, gender-based violence and STI services (information, testing and treatment). 100\% of clients were provided counselling on dual protection, with $61 \%$ receiving HIV and AIDS test counselling.

Table 8 provides with an indication of $\mathrm{SRH}$ related services that were observed being provided to clients.

TABLE 8: SRH services that were offered to clients seeking family planning services at the PSZ outreach sites

\section{SRH Services $(\mathrm{N}=655)$}

HIV and AIDS test counselling

Counselling on dual protection

Breast Cancer \& other gynecological issues

Pregnancy testing

Gender-based violence

STI services (information, testing and treatment)
Responses \% (n)

$$
\begin{gathered}
61 \%(n=399) \\
100 \%(n=655) \\
62 \%(n=406) \\
27 \%(n=176) \\
12 \%(n=78) \\
58 \%(n=379)
\end{gathered}
$$

Data Source: Client Provider Observation 


\subsection{Adverse events}

Information on adverse events (including side effects and complications) was collected on the Day 15 follow up visit using the client follow up interview tool (see Appendix). Interviewers asked about the existence and severity of symptoms from the day of the procedure up to and including Day 15 follow up. 91\% $(n=555)$ of clients returned on Day 15 and completed the follow up questionnaire.

Clients were asked to indicate the symptoms that they experienced on day of the procedure; post procedure (between the day of the procedure and the 15 day follow up visit) and whether the symptoms were still present at the 15 day follow up visit. It should be noted, that client reports were not verified by clinical or client-provider observation in relation to the medical intervention required. For this study, based on the clients' self-reported symptoms and level of intervention, adverse events were categorised as "very mild", "mild", "moderate" or" severe" per Table 5 (see page 15).

\section{Occurrence and frequency of side effects}

$65 \%(n=386)$ of all clients reported experiencing symptoms at some point between the day of the procedure and Day 15. Most clients reported experiencing side effects on the day of the procedure and indicated they were expected. $32 \%(n=180)$ of clients indicated that they experienced a side effect up to Day 15. Among implant acceptors, 32\% experienced some side effect on the day of the procedure and $21 \%$ stated they experienced side effects between the day of the procedure and the 15 day visit. $3 \%(n=16)$ of these clients stated they still experienced the side effect, however, only one client had to have their family planning method removed. Among tubal ligation acceptors $(n=7)$, one reported still experiencing the side effect at Day 15.

\section{Adverse events on day of procedure}

The summary of adverse events reported on the day of the procedure is detailed in Table 9. Amongst the implant clients 32\% $(n=168)$ reported experiencing pain. $17 \%(n=89)$ were categorised as experiencing "moderate" pain, requiring something stronger than paracetamol. 1\% $(n=6)$ self-reported taking pain relief medication for symptoms, which was categorised as "mild" side effects and 14\% $(n=73)$ reported slight pain (categorised as "very mild") which they had experienced only during the insertion of the Implant.

All tubal ligation clients experienced some amount of pain on the day of the procedure. $71 \%$ of tubal ligation clients experienced pain that was either "very mild" or "mild" at the time of the procedure. 14\% experienced moderate pain and no clients experienced "severe" pain.

IUD clients reported that some of them $(2 \%, n=7)$ experienced "severe" pain on the day of the procedure.

Bleeding that was categorised as "very mild" was reported for $94 \%$ of implant acceptors and $27 \%$ of IUD acceptors (including a combination of bleeding at insertion site and vaginal bleeding). Of the IUD clients that reported bleeding, $1 \%(n=3)$ reported that they experienced bleeding which lasted up to three days from the day of the procedure.

\section{Adverse events on Day 15 post procedure}

All tubal ligation clients returned for the 15 day follow up visit. $57 \%(n=4)$ and $29 \%(n=2)$ of clients reported experiencing pain and bleeding respectively. One client was recorded as experiencing mild haematoma or bruising but no treatment was required. One other client experienced bruising that required wound revision and the release of build-up of blood.

At Day 15, as compared to tubal ligation acceptors, a higher proportion of IUD clients reported side effects, such as pain and bleeding. 73\% $(n=35)$ of IUD clients reported experiencing some type of pain. $62 \%$ of these clients were categorised as reporting either "very mild" or "mild" pain. 10\% of these clients were categorised as experiencing "moderate" pain. Three clients reported still "experiencing severe cramping pains", and three clients reported "abdominal pain during intercourse since IUD insertion". Two clients reported experiencing "slight temperature and fever, abdominal pain, unusual discharge developed within the 15 days following IUD insertion", one client reported experiencing a "constant high temperature (required antibiotics and improved within seven days)" and another client reported experiencing "no improvement after seven days of antibiotic treatment". 
TABLE 9: Types of adverse events experienced on the day of procedure

\begin{tabular}{|c|c|c|c|c|}
\hline \multicolumn{2}{|c|}{$\begin{array}{l}\text { Signs and symptoms reported experienced } \\
\text { on day of procedure }\end{array}$} & $\begin{array}{l}\text { Implants } \\
\text { (Jadelle) } \\
(\mathrm{N}=532)\end{array}$ & $\begin{array}{c}\text { IUD } \\
(\mathrm{N}=48)\end{array}$ & $\begin{array}{l}\text { Tubal ligation } \\
\qquad(\mathrm{N}=7)\end{array}$ \\
\hline \multirow[t]{4}{*}{ Pain } & Very Mild & $14 \%$ & $2 \%$ & $29 \%$ \\
\hline & Mild & $1 \%$ & $1 \%$ & $43 \%$ \\
\hline & Moderate & $17 \%$ & - & $14 \%$ \\
\hline & Severe & & $1 \%$ & - \\
\hline \multicolumn{2}{|c|}{ Total "Pain" side effect } & 168 & 17 & 7 \\
\hline \multirow[t]{4}{*}{ Bleeding } & Very Mild & $94 \%$ & $27 \%$ & $14 \%$ \\
\hline & Mild & $6 \%$ & $2 \%$ & 0 \\
\hline & Moderate & 0 & 0 & 0 \\
\hline & Severe & 0 & $1 \%$ & 0 \\
\hline \multicolumn{2}{|c|}{ Total "bleeding" side effect } & 206 & 24 & 1 \\
\hline
\end{tabular}

Data source: 15 day follow up interview

TABLE 10: Types of adverse events experienced at 15 days post procedure

\begin{tabular}{|c|c|c|c|c|}
\hline & & $\begin{array}{l}\text { Implants } \\
(n=532)\end{array}$ & $\begin{array}{c}\text { IUD } \\
(\mathrm{N}=48)\end{array}$ & TL $(n=7)$ \\
\hline \multirow[t]{4}{*}{ Pain } & Very Mild & $15 \%(n=79)$ & $27 \%(n=13)$ & $29 \%(n=2)$ \\
\hline & Mild & $5 \%(n=25)$ & $35 \%(n=17)$ & $14 \%(n=1)$ \\
\hline & Moderate & $1 \%(n=4)$ & $10 \%(n=5)$ & $14 \%(n=1)$ \\
\hline & Severe & $0 \%(n=1)$ & - & - \\
\hline \multicolumn{2}{|c|}{ Total "pain" side effects reported } & 109 & 35 & 4 \\
\hline \multirow{4}{*}{$\begin{array}{l}\text { Bleeding at insertion } \\
\text { site for "Implants } \\
\text { and Tubal Ligation" \& } \\
\text { "Vaginal bleeding" } \\
\text { for IUD }\end{array}$} & Very Mild & $2 \%(n=8)$ & $35 \%(n=17)$ & $14 \%(n=1)$ \\
\hline & Mild & - & $8 \%(n=4)$ & - \\
\hline & Moderate & - & $2 \%(n=1)$ & - \\
\hline & Severe & - & - & $15 \%(n=1)$ \\
\hline \multicolumn{2}{|c|}{ Total "bleeding" side effects reported } & 8 & 22 & 2 \\
\hline
\end{tabular}


TABLE 11: Implant clients self-report on menstrual bleeding and breast tenderness

Menstrual bleeding

\begin{tabular}{|r|c|}
\hline $\begin{array}{r}\text { Lighter, fewer days, irregular and infrequent } \\
\text { Prolonged bleeding that lasts longer than } 8 \text { days }\end{array}$ & $8 \%(n=45)$ \\
\hline Heavier bleeding that is 2 times as usual & $3 \%(n=17)$ \\
\hline Heavy or prolonged bleeding continuing & $1 \%(n=6)$ \\
\hline Change in breast since Implants & $2 \%(n=12)$ \\
\hline New lump in breast since Implants inserted & $0.17 \%(n=1)$ \\
\hline Breast tenderness \& soreness & $0.3 \%(2)$ \\
\hline
\end{tabular}

Of the 532 implant clients who participated in the follow-up interview on Day 15, 64\% (338) reported some level of pain at some point in time. There were no reports of bleeding at Day $15.15 \%(n=79)$ of clients reported pain that continued for more than one day post-procedure. This side effect was categorised as a "very mild" side effect.

Information was collected from implant acceptors related to menstrual bleeding and breast tenderness (see Table 12). 3\% $(n=17)$ of clients experienced prolonged bleeding lasting longer than eight days.

\subsection{Follow up care and health seeking behaviour by Day 15}

All clients who attended the follow up visit and reported experiencing an adverse event were asked whether they sought care irrespective of the level of severity. $96 \%$ of clients reported that no care or additional treatment was required for their side effect. Figure 6 shows the reasons clients cited for not seeking care. Most clients indicated that they did not get time off from their household chores to seek care. Additionally, lack of concern from their partners or family members and thinking that the side effect symptoms will subside over time, were cited as well. Two percent $(n=8)$ of clients reported seeking care at a health facility however only $63 \%(n=5)$ reported that they were satisfied with the help that they had received and the remainder of the clients who were not satisfied, cited that they still experienced the side effect at the Day 15 follow up visit.

Another 2\% $(n=8)$ reported that they had contacted PSZ to discuss care and treatment. All these clients reported that they were advised to return to the health care facility and see a facility provider, should their symptoms continue, however only $50 \%(n=4)$ of these clients returned to the facility and were seen by a facility provider prior to the Day 15 follow up. These clients reported that the facility provider dispensed "pain medication" and that they received counselling and were asked to return at the Day 15 follow up and report to the PSZ provider any side effects that they were still experiencing.

The $50 \%$ of clients who did not return to the facility indicated that the facility was too far and that they would wait for the Day 15 follow up visit to return to the clinic.

A review of the side effects of the $2 \%$ of clients that contacted PSZ indicated that the "pain" \& "bleeding around the insertion site" was reported, however these symptoms had subsided and these symptoms were no longer experienced at the 15 day follow up visit. 
FIGURE 6: Reasons for clients not seeking health care when experiencing adverse event

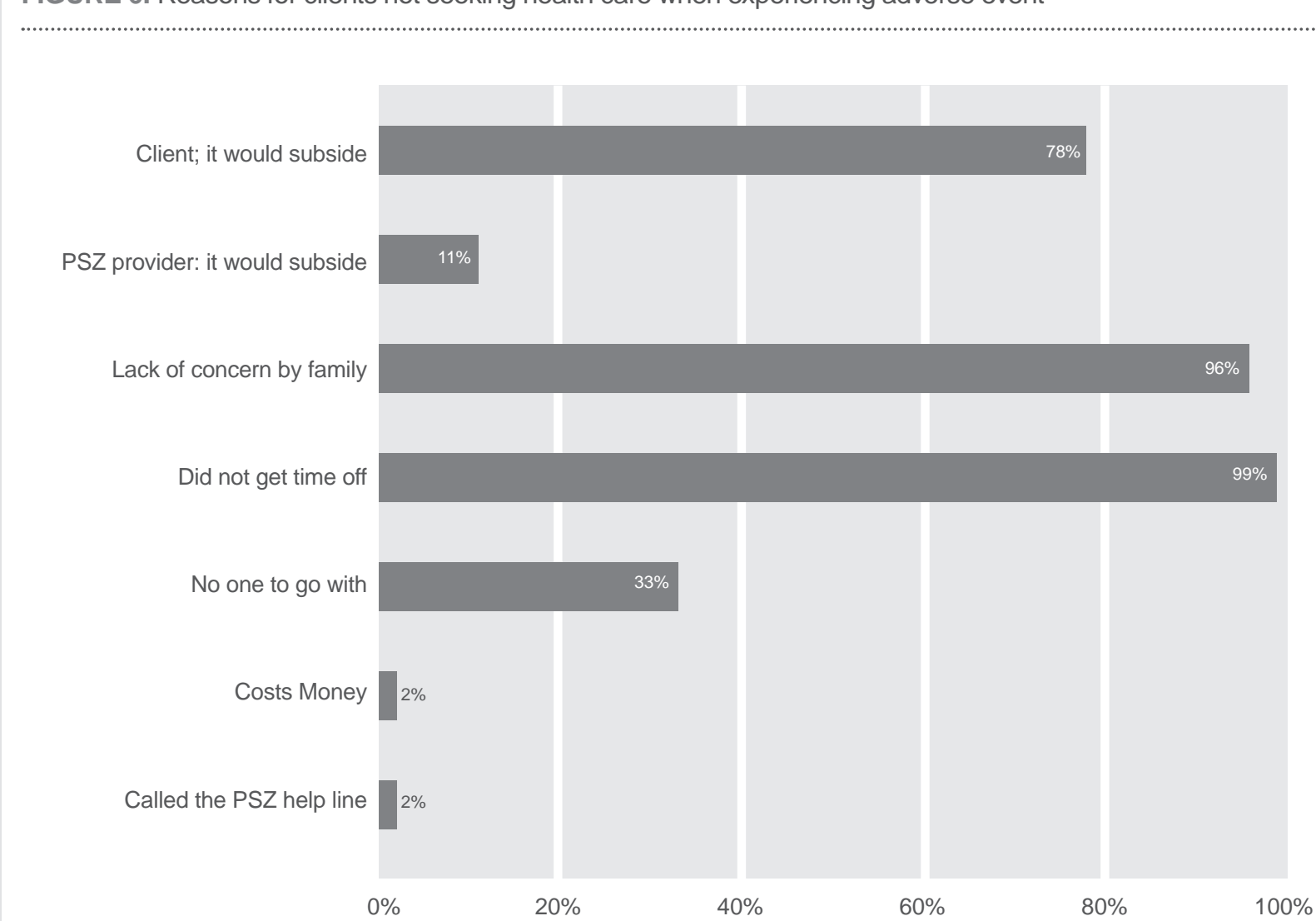

Data Source: 15 Day Follow-Up tool

\section{Resumption of normal activities and work}

$7 \%(n=3)$ of the IUD clients, and $2 \%(n=8)$ of implant clients reported that they were still unable to work as normal on Day 15 post-procedure. Of the clients who reported being unable to work, two IUD clients and four of the implant clients attributed this to pain, one of the IUD clients and three of the implant clients said it was due to insertion site bleeding, and $7 \%(n=3)$ of IUD clients and $0.4 \%(n=2)$ of implant clients reported "back ache" as the reason for non-resumption of normal activities and work.

\subsection{Myths and misconceptions}

All clients were asked whether they agreed with common misconceptions of family planning at the client exit interview. It was interesting to note that a large percentage of clients (52\%) thought that "condoms often break during sex". Some commonly reported beliefs included: women who have never had a baby cannot use an IUD or DMPA and IUDs cause discomfort to the partner during sex. Some clients felt that hormonal contraceptives could cause cancer and as many as $29 \%$ of clients said pills can make a woman sterile. Detailed findings on myths and misconceptions are shown in Table 12. 
TABLE 12: Myths and misconceptions as reported by the client

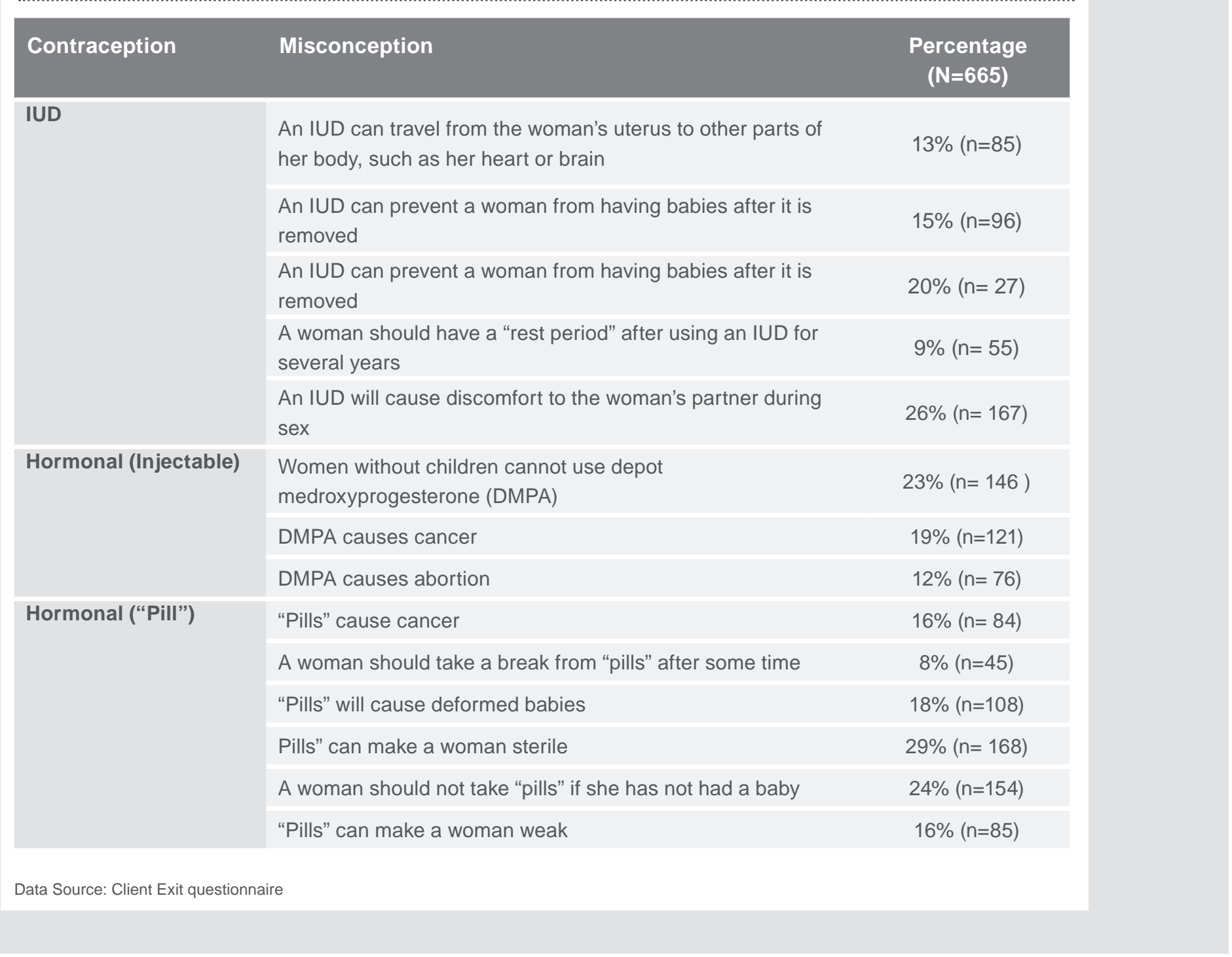




\section{Discussion and recommendations}

\subsection{Discussion}

PSZ mobile outreach services are an ideal platform to provide clients with integrated services especially around HIV and STIs. Clients are offered a full method mix of contraception during PSZ visits, but the uptake of IUD, tubal ligation and Implants tends to be high as other short acting methods of contraception are routinely available to women through the $\mathrm{MOHCC}$ service delivery. The study has shown that levels of satisfaction with PSZ services are high and there are low levels of severe adverse events. The analysis indicated that clients received accurate family planning information and that they were happy with the quality and quantity of information pertaining to their choice of family planning including how to manage common side effects.

\section{Quality of care}

The analysis revealed that in the majority of cases (83\%), providers encouraged clients to ask questions to establish their understanding of family planning. This interaction and discourse may have contributed to clients indicating that they would return to the site for family planning services as a strong rapport was often built. All providers were observed taking the client's medical history and, the data revealed that some information - such as obstetric information - was taken for a large percentage of clients. Although all clients (100\%) stated that they were happy and satisfied with the family planning service, not all clients indicated that they would refer a friend or a family member to the family planning site. $21 \%$ of clients indicated that they would refer the service to a stranger. It is likely that clients indicated low referral to family, friends and strangers due to family planning being considered a personal issue that should not be discussed with others. With regard to integration of other SRH services, $61 \%$ of clients were asked about risk factors for HIV, offered or referred for an HIV test. Given the high prevalence of HIV in this sexually active client population accessing contraceptive services, there is room for strengthening this aspect of service provision.

\section{Incidence of side effects}

The analysis revealed that clients were informed and knowledgeable about potential side effects and what action to take should they experience a side effect.
Most clients (94\%) received information on what to do if they experienced a side effect, and the information was relevant to their contraceptive method. Client's health-seeking behaviour was documented by what they did before arriving at the clinic for their Day 15 visit. The data showed that clients were able to seek assistance when they experienced a side effect as they knew how to access the facility and $2 \%$ of clients called the PSZ helpline. $65 \%(n=386)$ of clients reported experiencing symptoms at some point between the day of the procedure and Day 15. Most clients reported experiencing side effects on the day of the procedure and indicated they were expected. $32 \%$ $(n=180)$ of clients indicated that they experienced a side effect up to Day 15.

\section{Study limitations}

This study provided an overall indication of the quality of family planning services (objective 1) and the timing, frequency and type of side effect/s (objective 2) experienced. Certain limitations were encountered.

Clients who returned to the facility prior to the 15-day follow-up visit were unable to provide complete information about their consultation/visit with the facility providers. This included the type of treatment received and the purpose of the drugs dispensed for the side effect that they were experiencing. The study relied on self-reporting by the client. The study did not track the follow-up care of the $1 \%$ of clients who had their family planning method removed due to side effects experienced. The study also did not explore why, despite being satisfied with the service and willing to use it again, only $68 \%$ of clients indicated that they would refer the family planning service to a friend, 57\% would tell a family member about the family planning services and $21 \%$ would tell a stranger about the service.

The follow up period of 15 days was short, and therefore the study does not provide a good reflection of longer term side effects, such as changes in menstrual bleeding which may emerge over time, or of discontinuation behaviours over a longer term.

Due to the small sample size (related to the duration and available resources for the study) it was not possible to further analyse the characteristics of the clients who experienced side effects from IUDs and 
ultimately discontinued the method. Due to the follow up processes in the study design, it was difficult to further determine the exact cause of the (small) number of side effects.

While clients were asked about receiving their preferred family planning method, their reasons for seeking family planning services and rationale for the selected method were not explored in this study.

Partner, spouse or family member involvement was not addressed in this study as it is known that women are not only influenced or informed by their choice of method by providers but by close family members as well.

As with other prospective studies measuring post procedure outcomes, without strict medical verification and control, it is difficult to differentiate side effects as a result of the procedure from symptoms relating to the clients' conditions or living environment that may exacerbate the client's experience of side effects.

\subsection{Conclusion}

The study aimed to evaluate the quality of care provided by PSZ mobile outreach model in Zimbabwe. The findings reveal that PSZ provides a critical health service to women, especially those between the age of 15 years and 29 years who live in rural areas. PSZ mobile teams expand access and choice of family planning methods to women who otherwise would not receive these services. Overall, clients indicated that they were satisfied with the quality of services they received from PSZ. Clients were well informed on how to manage side effects and their health-seeking behaviour attested to this. In addition, health-seeking behaviour such as seeking care at the facility, calling the PSZ helpline and returning at the 15 day follow-up visit (which was facilitated by the study and does not happen during normal operations) is an indication that women are aware of how to seek care and what to do in the event of a side effect. Determining access to care was also assessed and the data revealed that the women received the service they needed when they arrived at the facility or the mobile site. At the Day 15 follow up, one woman experienced a severe side effect (an implant user reporting pain) and no complications were reported amongst those clients interviewed. These rates are similar to other published studies of the experiences of mobile outreach clients $[16,17]$. This study also highlighted areas of service that require strengthening and opportunities to improve integrated SRH service delivery such as testing and re-testing for HIV, partner involvement and STI treatment and care and the potential to provide more information on other sexual and reproductive health issues.

\subsection{Recommendations}

It is recommended that PSZ consider the following to strengthen services:

- Clients are at significant risk of HIV and there is an opportunity to integrate more information and HIV related services into the routine family planning consultation.

- A significant proportion of clients continue to have misconceptions and incorrect information about various contraceptive methods. PSZ health care providers should continue to focus on correcting myths and misconceptions routinely in group or individual counselling as part of their family planning community outreach activities.

- Although in some instances providers are using the family planning consultation to integrate information on other sexual and reproductive health issues, there is room for strengthening this component and reducing missed opportunities to provide information. 


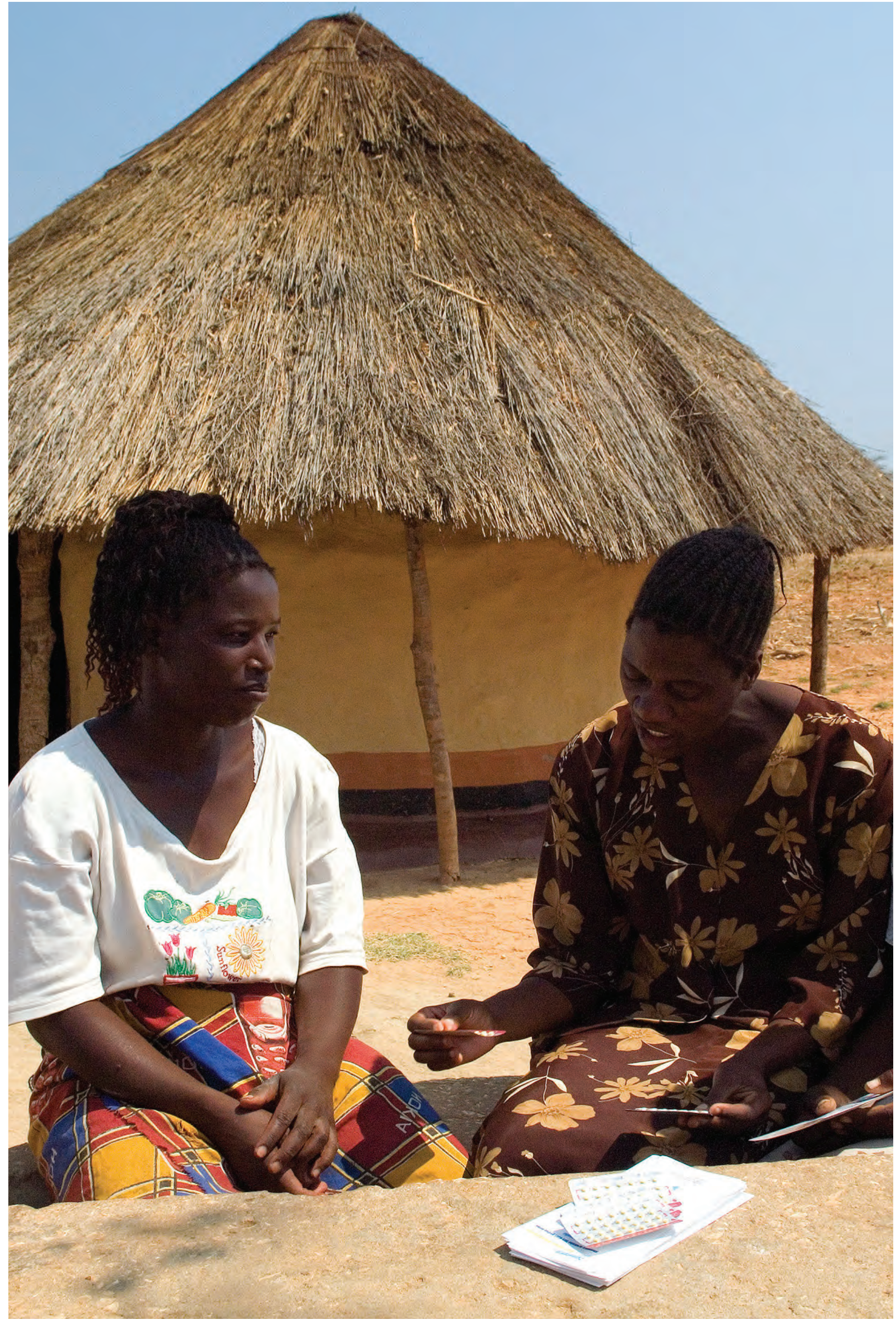




\section{References}

1. Zimbabwe National Statistics Agency (ZIMSTAT) and ICF International. 2012. Zimbabwe Demographic and Health Survey 2010-11. Retrieved from: http://www.zimstat.co.zw/ dmdocuments/Census/CensusResults2012/ National_Report.pdf

2. Zimbabwe National HIV and AIDS Strategic Plan 2011-2015. Retrieved from http://www.safaids.net/ files/ZNASP_II_2011-2015.pdf.

3. Central Statistical Office (CSO) [Zimbabwe] and Macro International Inc. 2007. Zimbabwe Demographic and Health Survey 2005-06. Calverton, Maryland: CSO and Macro International Inc.

4. UNFPA: Zimbabwe, (2012). Committing to making universal access to family planning services a reality in Zimbabwe. Retrieved from: http:// countryoffice.unfpa.org/ zimbabwe/2012/08/03/5353/commiting_to making_universal_access_to_family_planning_ services_a_reality_in_zimbabwe/

5. World Bank Indicators, 2011. Contraceptive prevalence (\% of women ages 15-49) in Zimbabwe. Retrieved from: www. tradingeconomics.com/zimbabwe/contraceptiveprevalence-percent

6. Murwira, M., 2011. Zimbabwe Population Stabilisation Report. Retrieved from: http://www. populationcommunication.com/Medias/ Zimbabwe_report.pdf

7. National Research Council. Factors Affecting Contraceptive Use in Sub-Saharan Africa. Washington DC: National Academy Press, 1993

8. Guilkey DK and Jayne S. Fertility transition in Zimbabwe: determinants of contraceptive use and method choice. Population Studies 1997; 51(2): 173-189.

9. Muhwava, M., 2003. Patterns of Contraceptive Use at the Edge of Fertility Transition in Zimbabwe. African Population Studies vol. 18 n¹
10. Ministry of Health and Child Welfare, Zimbabwe National HIV Estimates, June 2010

11. Horney, J. 2003. HIV Prevalence and High Contraceptive Prevalence Rates in Botswana, Kenya and Zimbabwe: Is this Relationship Counterintuitive Considering the Determinants for HIV and CPR and the Populations Included in Prevalence Measurements? Carolina Papers in International Health. Retrieved from: http://cgi.unc. edu/uploads/media_items/hiv-prevalence-andhigh-contraceptive-prevalence-rates-in-botswanakenya-and-zimbabwe-is-this-relationshipcounterintuitive-considering-the-determinants-forhiv-and-cpr-and-the-populations.original.pdf

12. Fraser, N., Ruark, A.H. \& Gorgens, M. ZIMBABWE: Analysis of HIV Epidemic, Response and Modes of Transmission. 2011

13. Zimbabwe National HIV and AIDS Strategic Plan 2011-2015

14. Ramjee, G. \& Daniels, B., 2013. Women and HIV in Sub-Saharan Africa. AIDS Research and Therapy 2013, 10:30. Retrieved from: http://www. aidsrestherapy.com/content/10/1/30

15. Zimbabwe: Health Impact. 2013. Retrieved from: http://www.psi.org/zimbabwe

16. Eva, G., \& Ngo, T., MSI Mobile Outreach Services: Retrospective evaluations from Ethiopia, Myanmar, Pakistan, Sierra Leone and Vietnam. 2010, Marie Stopes International: London.;

17. Aruldas, K., Khan, M. E., Ahmad, J., \& Dixit, A., (2014). Increasing choice and access to family planning services via outreach in Rajasthan, India: An evaluation of MSI India's outreach services New Delhi, India: Population Council. 
Marie Stopes International

1 Conway Street

Fitzroy Square

London W1T 6LP

$\mathrm{t}:+44(0) 2076366200$

f: +44 (0)20 70342369

e: info@mariestopes.org

w: www.mariestopes.org

Registered charity number: 265543

Company number: 1102208
Population Council

One Dag Hammarskjold Plaza

9th Floor

New York, NY 10017

USA

t: +1 2123390500 